Article

\title{
New Chlorinated 2,5-Diketopiperazines from Marine-Derived Bacteria Isolated from Sediments of the Eastern Mediterranean Sea
}

\author{
Maria Harizani, Eleni Katsini, Panagiota Georgantea, Vassilios Roussis $\mathbb{D}$ and \\ Efstathia Ioannou *(D)
}

Section of Pharmacognosy and Chemistry of Natural Products, Department of Pharmacy, School of Health Sciences, National and Kapodistrian University of Athens, Panepistimiopolis Zografou, Athens 15771, Greece; mariachariz@pharm.uoa.gr (M.H.); ekatsini@pharm.uoa.gr (E.K.); ggeorgantea@yahoo.gr (P.G.); roussis@pharm.uoa.gr (V.R.)

* Correspondence: eioannou@pharm.uoa.gr; Tel.: +30-210-727-4913

Academic Editor: Valeria Costantino

Received: 9 March 2020; Accepted: 23 March 2020; Published: 26 March 2020

\begin{abstract}
From the organic extracts of five bacterial strains isolated from marine sediments collected in the East Mediterranean Sea, three new $(15,16,31)$ and twenty-nine previously reported (1-14, 17-30,32) metabolites bearing the 2,5-diketopiperazine skeleton were isolated. The structures of the chlorinated compounds 15, 16, and $\mathbf{3 1}$ were elucidated by extensive analysis of their spectroscopic data (NMR, MS, UV, IR). Compounds $\mathbf{1 5}$ and 16 were evaluated for their antifungal activity against Candida albicans and Aspergillus niger but were proven inactive. The relevant literature is supplemented with complete NMR assignments and revisions for the 29 previously reported compounds.
\end{abstract}

Keywords: 2,5-diketopiperazine; marine bacteria; sediment; natural products; structure elucidation; antifungal activity evaluation

\section{Introduction}

2,5-Diketopiperazines (DKPs), also termed as cyclodipeptides, 2,5-dioxopiperazines, or dipeptide anhydrides, are the smallest possible cyclic peptides and, therefore, are among the most common peptide derivatives found in nature. They derive from the condensation of two $\alpha$-amino acids forming a bis-lactam. Although they are relatively simple and low molecular weight compounds, they can be highly substituted, resulting in complex structures [1,2]. DKPs have been reported, so far, from a variety of sources, including microorganisms (bacteria and fungi), as well as higher organisms (algae, lichens, plants, marine sponges, gorgonians, tunicates, and mammals) [3,4]. They are also found in food and beverages, lending them a bitter taste [5]. The origin of DKPs has been questioned and it has been proposed that they might even be chemical degradation products. However, sterile media do not contain DKPs [6-9] and specific bacterial genes encode their biosynthesis [10-12].

DKPs have been neglected for many years, but they have recently attracted attention due to their chemical diversity and remarkable bioactivity. They exhibit a wide range of biological activities, such as cytotoxic, antibacterial, antifungal, antiparasitic, insecticidal, antiviral, antiprion, antifouling, antioxidant, anti-inflammatory, antihyperglycemic, and neuroprotective; thus, making them promising drug candidates. Moreover, they are involved in quorum sensing and ion-transport, and exhibit high binding affinity to a large number of receptors [4,13-17].

The DKP chiral scaffold is attractive for drug design due to its simplicity, high stability (resistance to proteolysis), conformational rigidity, and remarkable structural diversity [18]. DKPs are readily accessible by chemical synthesis, constituting an excellent model for theoretical studies and an 
important pharmacophore in medicinal chemistry $[4,13,19]$. Moreover, they are employed as starting materials for the synthesis of many natural products, such as alkaloids [18].

Three drugs based on this scaffold have recently entered the market, namely tadalafil, as a phosphodiesterase-5 inhibitor for the treatment of erectile dysfunction [20], retosiban, as an oxytocin antagonist for the treatment of preterm labor [21], and epelsiban, as an oxytocin antagonist for the treatment of premature ejaculation in men [22]. Additionally, it has been shown that their presence in culture broths fermented with lactic acid bacteria (LAB) can greatly contribute to an environmentally friendly, safe, and ecological approach for food and feed preservation [23].

In the framework of our investigations towards the isolation of new bioactive secondary metabolites from marine microorganisms, a large number of bacterial strains have been isolated from marine sediments collected from the East Mediterranean basin, a relatively unexplored marine ecosystem regarding the chemistry of its microbiota. The preliminary screening of the chemical profiles of extracts obtained from small-scale liquid cultures of a large number of marine-derived bacterial strains from our microbank with LC-DAD-MS and NMR led to the selection of five strains for further chemical investigation. Extraction of large-scale cultures of the selected bacterial strains and fractionation of the obtained organic extracts allowed for the isolation of 32 DKPs (Figures 1 and 2), among which three chlorinated analogues $(\mathbf{1 5}, \mathbf{1 6}$, and 31) were identified as new natural products. Herein, we report the isolation and structure elucidation of metabolites 15, 16, and 31 and the evaluation of the antifungal activities of $\mathbf{1 5}$ and 16. Additionally, since several inconsistencies in the published NMR data of DKP structures are frequently observed, in conjunction with the fact that NMR data is incompletely reported for several of these, leading to confusion, complete assignment of the ${ }^{1} \mathrm{H}$ and ${ }^{13} \mathrm{C}$ NMR chemical shifts of the known metabolites $\mathbf{1 - 1 4}, \mathbf{1 7 - 3 0}$, and $\mathbf{3 2}$ is also presented.

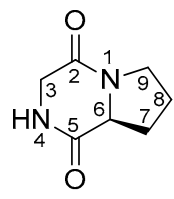

cyclo(Pro-Gly)

(1)

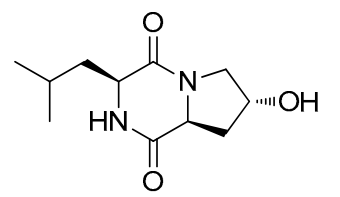

cis-cyclo(trans-4-Hyp-Leu)

(6)<smiles>[R]S(=O)CC[C@@H]1NC(=O)[C@@H]2CCCN2C1=O</smiles>

cis-cyclo(Pro-OMet)

(10)<smiles>O=C1N[C@@H](Cc2ccc(O)cc2)C(=O)N2CCC[C@H]12</smiles>

(14)<smiles>O=C1N[C@@H](O)C(=O)N2CCC[C@@H]12</smiles>

(2)

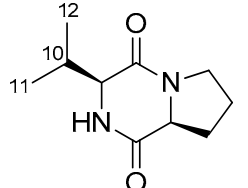

cis-cyclo(Pro-Val)

(3)

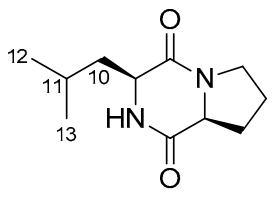

cis-cyclo(Pro-Leu)

(4)<smiles>[Z]CC(C)[C@H]1NC(=O)[C@@H]2CCCN2C1=O</smiles>

cis-cyclo(Pro-lle)

(8)<smiles>O=C1N[C@@H](Cc2ccccc2)C(=O)N2CCC[C@H]12</smiles>

trans-cyclo(Pro-Phe)

(12)<smiles>O=C1N[C@H](Cc2ccc(O)c(Cl)c2)C(=O)N2CCC[C@H]12</smiles>

(16)<smiles>CC(C)C[C@@H]1NC(=O)[C@@H]2CCCN2C1=O</smiles>

(5)<smiles>CCC(C)[C@H]1NC(=O)[C@@H]2CCCN2C1=O</smiles>

trans-cyclo(Pro-lle)

(9)<smiles>O=C1N[C@@H](Cc2ccccc2)C(=O)N2C[C@H](O)C[C@H]12</smiles>

cis-cyclo(trans-4-Hyp-Phe)

(13)<smiles>O=C1N[C@@H](Cc2ccc(O)c(Cl)c2)C(=O)N2CCC[C@H]12</smiles>

(15)<smiles>O=C1N[C@@H](Cc2c[nH]c3ccccc23)C(=O)N2CCC[C@H]12</smiles>

cis-cyclo(Pro-Trp)

(17)

Figure 1. Chemical structures of compounds 1-17 isolated from various marine-derived bacterial strains. 
<smiles>CC(C)CC1NC(=O)CNC1=O</smiles>

(18)<smiles>CC(C)CC1NC(=O)[C@H](C)NC1=O</smiles>

(19)<smiles>CC[C@H](OC(=O)OC(=O)[O-])[C@H]1NC(=O)[C@@H](C)NC1=O</smiles>

(20)<smiles>CC(C)CC1NC(=O)C(C(C)C)NC1=O</smiles>

(21)<smiles>CC(C)C[C@@H]1NC(=O)[C@@H](CC(C)C)NC1=O</smiles>

(22)<smiles>CCC(C)C1NC(=O)C(CC(C)C)NC1=O</smiles><smiles>C[C@H]1NC(=O)C(Cc2ccccc2)NC1=O</smiles>
cis-cyclo(Phe-Ala) (24)<smiles>O=C1N[C@H](CO)C(=O)N[C@H]1Cc1ccccc1</smiles>
cis-cyclo(Phe-Ser) (25)

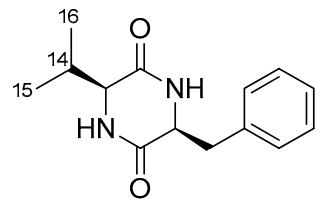

cis-cyclo(Phe-Val)

(26)<smiles>CC(C)C[C@H]1NC(=O)C(Cc2ccccc2)NC1=O</smiles>

(27)<smiles>CCC(CC)[C@H]1NC(=O)[C@@H](Cc2ccccc2)NC1=O</smiles>

(28)<smiles>CC(C)C[C@H]1NC(=O)[C@H](Cc2ccc(O)cc2)NC1=O</smiles>

(29)<smiles>CC(C)[C@H]1NC(=O)[C@@H](Cc2ccc(O)cc2)NC1=O</smiles>

(30)<smiles>CCC(C)[C@H]1NC(=O)C(Cc2ccc(O)c(Cl)c2)NC1=O</smiles>

cis-cyclo(3-chloro-Tyr-lle)

(31)<smiles>O=C1N[C@H](Cc2ccccc2)C(=O)N[C@H]1Cc1ccccc1</smiles>

(32)

Figure 2. Chemical structures of compounds 18-32 isolated from various marine-derived bacterial strains.

\section{Results and Discussion}

The organic extracts of five marine-derived bacterial strains, specifically Bacillus endophyticus BI0327, Streptomyces albidoflavus BI0383, Nocardiopsis aegyptia BI0618, Streptomyces smyrnaeus BI0918, and Bacillus subtilis BI0980, isolated from marine sediments collected in the Aegean and Ionian seas, were subjected to repetitive chromatographic fractionations to yield three new natural products, namely cis-cyclo(Pro-3-chloro-Tyr) (15), trans-cyclo(Pro-3-chloro-Tyr) (16), and cis-cyclo(3-chloro-Tyr-Ile) (31), and 29 previously reported metabolites, which were identified as cyclo(Pro-Gly) (1) [24,25], cis-cyclo(Pro-Ala) (2) [26,27], cis-cyclo(Pro-Val) (3) [28-30], cis-cyclo(Pro-Leu) (4) [25,29,31,32], trans-cyclo(Pro-Leu) (5) [31,33], cis-cyclo(trans-4-Hyp-Leu) (6) [34], trans-cyclo(cis-4-Hyp-Leu) (7) [35], cis-cyclo(Pro-Ile) (8) [28,31,36], trans-cyclo(Pro-Ile) (9) [36,37], cis-cyclo(Pro-OMet) (10) [38], cis-cyclo(Pro-Phe) (11) $[28,30,31,39,40]$, trans-cyclo(Pro-Phe) (12) [33,36,40], cis-cyclo(trans-4-Hyp-Phe) (13) [36,41], cis-cyclo(Pro-Tyr) (14) [42,43], cis-cyclo(Pro-Trp) (17) [44,45], cyclo(Leu-Gly) (18) [46-48], cis-cyclo(Leu-Ala) (19) [49,50], cis-cyclo(Ile-Ala) (20) [49], cis-cyclo(Leu-Val) (21) [37], cis-cyclo(Leu-Leu) (22) [37,51,52], cis-cyclo(Leu-Ile) (23) [17], cis-cyclo(Phe-Ala) (24) [49], cis-cyclo(Phe-Ser) (25) [53], cis-cyclo(Phe-Val) (26) [17], cis-cyclo(Phe-Leu) (27) [17,54], cis-cyclo(Phe-Ile) (28) [17], cis-cyclo(Tyr-Leu) (29) [54], cis-cyclo(Tyr-Ile) (30) [17], and cis-cyclo(Phe-Phe) (32) [55] by comparison of their spectroscopic and physical characteristics with those reported in the literature.

Compound 15, obtained as white solid, displayed the molecular formula $\mathrm{C}_{14} \mathrm{H}_{15} \mathrm{~N}_{2} \mathrm{O}_{3} \mathrm{Cl}$, as deduced from high-resolution electrospray ionization mass spectrometry (HRESIMS) measurements where two isotopic sodium adduct ion peaks were observed at $\mathrm{m} / \mathrm{z} 317.0661$ and 319.0629 with a ratio of 3:1, characteristic for the presence of one chlorine atom in the molecule. The HSQC and HMBC experiments revealed 14 carbon signals, which corresponded to five non-protonated carbon atoms, 
among which two carbonyls resonating at $\delta_{\mathrm{C}} 164.7$ and 169.1, five methines, and four methylenes. The ${ }^{1} \mathrm{H}$ and ${ }^{13} \mathrm{C}$ NMR spectra (Tables 1 and 2 and Figures S1-S6) included signals at $\delta_{\mathrm{H}} 6.98(1 \mathrm{H}, \mathrm{d}, 8.2 \mathrm{~Hz})$, $7.03(1 \mathrm{H}, \mathrm{dd}, 8.2,2.0 \mathrm{~Hz})$, and $7.18(1 \mathrm{H}, \mathrm{d}, 2.0 \mathrm{~Hz})$ indicative of a 1,2,4-trisubstituted aromatic ring, whereas signals for two deshielded methines at $\delta_{\mathrm{H} / \mathrm{C}} 4.07 / 59.0$ and 4.21/55.8 and one exchangeable proton signal at $\delta_{\mathrm{H}} 5.55$, pointing to a DKP skeleton, were observed. The COSY correlations of $\mathrm{H}-6 / \mathrm{H}_{2}-7$, $\mathrm{H}_{2}-7 / \mathrm{H}_{2}-8$, and $\mathrm{H}_{2}-8 / \mathrm{H}_{2}-9$ supported the presence of a proline moiety, while further interpretation of the HMBC data unambiguously connected the spin systems (Figure 3) and verified the planar structure of 15. The NOE correlation of H-3 and H-6 determined their cis orientation and assigned the relative configuration of 15 that was identified as cis-cyclo(Pro-3-chloro-Tyr). Compound 15, described here for the first time as a natural product, has been previously reported as a synthetic derivative [43].

Compound 16, which also displayed two sodium adduct ion peaks at $m / z 317.0657$ and 319.0627 with a ratio of 3:1 (HRESIMS), was isolated as white solid. The spectroscopic characteristics of 16 (Tables 1 and 2 and Figures S7-S12) were rather similar to those of 15. Specifically, the NMR spectra of 16 revealed the same structural characteristics of a DKP moiety, including a proline amino acid and a 1,2,4-trisubstituted aromatic ring. The most prominent difference was that H-3 (4.13 ppm) and H-6 (3.22 ppm) resonated in higher fields, which, in combination with the absence of an NOE correlation between them, indicated that compound $\mathbf{1 6}$ was the trans isomer of $\mathbf{1 5}$. The COSY cross-peaks and the HMBC correlations observed for 16 (Figure 3), in accordance to those observed for compound 15, were in agreement with the proposed structure of trans-cyclo(Pro-3-chloro-Tyr).

Compound 31, was obtained in trace amounts as a 1:1 mixture with compound 30. The gas chromatography - electron ionization mass spectrometry (GC-EIMS) chromatogram included two peaks, the first displaying a molecular ion peak $[\mathrm{M}]^{+}$at $m / z 276$ and a fragmentation pattern identical to that of cis-cyclo(Tyr-Ile) (30), whereas the second displayed molecular ion peaks [M] ${ }^{+}$at $m / z 310$ and 312 with an isotopic ratio of 3:1, suggesting that $\mathbf{3 1}$ was a monochlorinated compound. Comparison of the ${ }^{1} \mathrm{H}$ NMR data of the mixture with that of cis-cyclo(Tyr-Ile) (30) in pure form revealed the structural similarity of metabolites $\mathbf{3 1}$ and 30, with the main difference observed in the aromatic ring (Tables 1 and 2 and Figures S13-S17). Indeed, in the aromatic region of the ${ }^{1} \mathrm{H}$ NMR spectrum, the signals at $\delta_{\mathrm{H}} 6.97(1 \mathrm{H}, \mathrm{d}, 8.3 \mathrm{~Hz}), 7.02(1 \mathrm{H}, \mathrm{br} \mathrm{d}, 8.3 \mathrm{~Hz})$, and $7.17(1 \mathrm{H}$, br s), indicative of a 1,2,4-trisubstituted aromatic ring, were assigned to compound 31, whereas two signals at $\delta_{\mathrm{H}} 6.79(\mathrm{~d}, 8.0 \mathrm{~Hz})$ and $7.07(\mathrm{~d}$, $8.0 \mathrm{~Hz}$ ), integrating for two protons each, were assigned to the protons of the $p$-substituted aromatic ring of compound 30. Analysis of the 2D NMR spectra (Figure 3) confirmed the residue of isoleucine and the proposed planar structure of 31, whereas comparison of the chemical shifts of H-3 $(\delta 3.90)$ and H-6 ( $\delta 4.19)$ to those of compound 30 indicated their cis orientation. Thus, compound 31 was identified as cis-cyclo(3-chloro-Tyr-Ile).

Since several inconsistencies are observed for the published NMR data of frequently isolated DKPs, in conjunction to the fact that NMR data are incompletely reported for a number of them, the ${ }^{1} \mathrm{H}$ and ${ }^{13} \mathrm{C}$ NMR data for the known compounds $\mathbf{1 - 1 4 , 1 7 - 3 0}$, and 32 are presented in Tables 1 and 2 , complementing and revising the relevant literature data. Through careful analysis of the ${ }^{13} \mathrm{C} \mathrm{NMR}$ chemical shifts of the proline-containing cis/trans pairs 4/5, 6/7, 8/9, 11/12, and 15/16, it can be observed that the chemical shifts of C-3 and C-10 are consistently deshielded by 3 and 3.5-4.5 ppm, respectively, in the trans DKP isomers. 
Table 1. (a) ${ }^{1} \mathrm{H}$ NMR data $\left(\delta\right.$ in ppm, $J$ in Hz) ${ }^{1}$ of compounds 1-8. (b) ${ }^{1} \mathrm{H}$ NMR data $(\delta$ in ppm, $J$ in $\mathrm{Hz}){ }^{1}$ of compounds 9-16. (c) ${ }^{1} \mathrm{H}$ NMR data $(\delta$ in ppm, $J$ in $\mathrm{Hz}){ }^{1}$ of compounds 17-24. (d) ${ }^{1} \mathrm{H}$ NMR data $(\delta \text { in ppm, } J \text { in } \mathrm{Hz})^{1}$ of compounds 25-32.

\begin{tabular}{|c|c|c|c|c|c|c|c|c|}
\hline Position & $1^{2}$ & $2^{2}$ & $3^{2}$ & $4^{2}$ & $5^{2}$ & $6^{2}$ & $7^{2}$ & $8^{2}$ \\
\hline 1 & - & - & - & - & - & - & - & - \\
\hline 3 & $\begin{array}{c}\text { 4.08, d (16.6) } \\
3.87, \mathrm{dd}(16.6,4.4)\end{array}$ & $4.12, \mathrm{~m}$ & $3.92, \mathrm{br} \mathrm{s}$ & $4.00, \mathrm{dd}(9.7,3.6)$ & 3.91, ddd $(9.7,5.5,4.4)$ & $4.04, \mathrm{dd}(9.6,3.8)$ & $3.95, \mathrm{~m}$ & $3.95, \mathrm{br} \mathrm{s}$ \\
\hline 4 & 6.32 , br s & $5.66, \mathrm{br} \mathrm{s}$ & $5.67, \mathrm{br} \mathrm{s}$ & $5.78, \mathrm{br} \mathrm{s}$ & $6.04, \mathrm{br} \mathrm{s}$ & $5.83, \mathrm{br} \mathrm{s}$ & $6.07, \mathrm{br} \mathrm{s}$ & $5.86, \mathrm{br} \mathrm{s}$ \\
\hline 6 & $4.07, \mathrm{~m}$ & $4.11, \mathrm{~m}$ & $4.07, \mathrm{t}(8.1)$ & $4.10, \mathrm{t}(8.2)$ & $4.07, \mathrm{dd}(9.4,6.8)$ & $4.48, \mathrm{dd}(11.1,6.3)$ & $4.16, \mathrm{dd}(9.2,5.6)$ & $4.05, \operatorname{brt}(8.0)$ \\
\hline 7 & $\begin{array}{l}2.36, \mathrm{~m} \\
2.05 \mathrm{~m}\end{array}$ & $\begin{array}{l}2.36, \mathrm{~m} \\
2.13, \mathrm{~m}\end{array}$ & $\begin{array}{l}2.37, \mathrm{~m} \\
2.02 \mathrm{~m}\end{array}$ & $\begin{array}{l}2.33, \mathrm{~m} \\
2.12 \mathrm{~m}\end{array}$ & $\begin{array}{l}2.38, \mathrm{~m} \\
2.02 \mathrm{~m}\end{array}$ & $\begin{array}{c}2.37, \text { br dd }(13.5,6.3) \\
2.14 \text { ddd }(13.5 .11 .14 .3)\end{array}$ & $2.48, \mathrm{~m}$ & $\begin{array}{l}2.36, \mathrm{~m} \\
2.02 \mathrm{~m}\end{array}$ \\
\hline 8 & $\begin{array}{l}2.00, \mathrm{~m} \\
1.90, \mathrm{~m}\end{array}$ & $\begin{array}{l}2.01, \mathrm{~m} \\
1.89, \mathrm{~m}\end{array}$ & $\begin{array}{l}2.02, \mathrm{~m} \\
1.89, \mathrm{~m}\end{array}$ & $\begin{array}{l}2.01, \mathrm{~m} \\
1.89, \mathrm{~m}\end{array}$ & $\begin{array}{l}2.02, \mathrm{~m} \\
2.02, \mathrm{~m} \\
1.88, \mathrm{~m}\end{array}$ & $\begin{array}{c}2.14, \mathrm{ddd}(13.5,11.1,4.3) \\
4.58(\mathrm{t}, 4.3)\end{array}$ & $4.46, \mathrm{~m}$ & $\begin{array}{l}2.02, \mathrm{~m} \\
1.89, \mathrm{~m}\end{array}$ \\
\hline 9 & $\begin{array}{l}3.61, \mathrm{~m} \\
3.53, \mathrm{~m}\end{array}$ & 3.56, m & $\begin{array}{l}3.62, \mathrm{~m} \\
3.53, \mathrm{~m}\end{array}$ & $3.55, \mathrm{~m}$ & $\begin{array}{l}3.63, \mathrm{~m} \\
3.51, \mathrm{~m}\end{array}$ & $\begin{array}{l}\text { 3.71, dd (13.2, 4.3) } \\
3.55, \mathrm{~d}(13.2)\end{array}$ & $\begin{array}{c}3.95, \mathrm{~m} \\
3.34, \mathrm{dd}(12.5,4.8)\end{array}$ & $\begin{array}{l}3.61, \mathrm{~m} \\
3.53, \mathrm{~m}\end{array}$ \\
\hline 10 & & $1.45, \mathrm{~d}(7.0)$ & 2.62, qqd $(7.3,6.9,2.7)$ & $\begin{array}{c}2.05, \mathrm{~m} \\
1.51, \operatorname{ddd}(14.5,9.7,5.0)\end{array}$ & $1.62, \mathrm{~m}$ & $\begin{array}{l}2.05, \text { ddd }(14.5,9.9,3.8) \\
1.50, \operatorname{ddd}(14.5,9.6,4.9)\end{array}$ & $1.62, \mathrm{~m}$ & $2.30, \mathrm{~m}$ \\
\hline 11 & & & $0.89, \mathrm{~d}(6.9)$ & $1.71, \mathrm{~m}$ & $1.75, \mathrm{~m}$ & $1.73, \mathrm{~m}$ & $1.74, \mathrm{~m}$ & $\begin{array}{l}1.41, \mathrm{~m} \\
1.14, \mathrm{~m}\end{array}$ \\
\hline 12 & & & $1.04, \mathrm{~d}(7.3)$ & $0.94, \mathrm{~d}(6.5)$ & $0.93, \mathrm{~d}(6.5)$ & $0.94, \mathrm{~d}(6.6)$ & $0.93, \mathrm{~d}(6.5)$ & $0.91, \mathrm{t}(7.4)$ \\
\hline 13 & & & & $0.98, \mathrm{~d}(6.5)$ & $0.97, \mathrm{~d}(6.5)$ & $0.99, \mathrm{~d}(6.6)$ & $0.96, \mathrm{~d}(6.5)$ & $1.03, \mathrm{~d}(7.2)$ \\
\hline 14 & & & & & & & & \\
\hline 15 & & & & & & & & \\
\hline 16 & & & & & & & & \\
\hline 17 & & & & & & & & \\
\hline 18 & & & & & & & & \\
\hline 19 & & & & & & & & \\
\hline 20 & & & & & & & & \\
\hline $\mathrm{OH}$ & & & & & & & & \\
\hline
\end{tabular}

${ }^{1}$ In $\mathrm{CDCl}_{3}$ for 1-28 and 30-32 and in $\mathrm{CD}_{3} \mathrm{OD}$ for $29 .{ }^{2}$ Recorded at $400 \mathrm{MHz} .{ }^{3}$ Recorded at $950 \mathrm{MHz} .{ }^{4}$ Recorded at $700 \mathrm{MHz} .{ }^{5}$ Recorded at $600 \mathrm{MHz}$. 
Table 1. Cont

(b)

\begin{tabular}{|c|c|c|c|c|c|c|c|c|}
\hline Position & $9^{2}$ & $10^{2}$ & $11^{2}$ & $12^{2}$ & $13^{2}$ & $14^{2}$ & $15^{3}$ & $16^{3}$ \\
\hline 1 & - & & & & - & & - & \\
\hline 3 & $3.77, \mathrm{dd}(5.4,3.9)$ & $4.19, \mathrm{~m}$ & $4.25, \mathrm{dd}(10.5,3.5)$ & $4.19, \mathrm{dt}(6.7,4.3)$ & $4.30, \mathrm{dd}(10.8,3.6)$ & $4.20, \mathrm{dd}(10.1,3.5)$ & $4.21, \operatorname{td}(10.0,3.3)$ & 4.13, ddd $(7.0,4.2,3.5)$ \\
\hline 4 & 6.19, br s & $7.43, \mathrm{~s}$ & $5.69, \mathrm{brs}$ & $5.76, \mathrm{br} \mathrm{s}$ & $5.57, \mathrm{br} \mathrm{s}$ & 5.85, br s & 5.55, br s & 5.75, br s \\
\hline 6 & $4.08, \mathrm{dd}(9.6,6.5)$ & $4.10, \mathrm{~m}$ & $4.05, \mathrm{t}(8.0)$ & $3.04, \mathrm{dd}(10.4,6.6)$ & $4.45, \mathrm{dd}(11.2,6.4)$ & $4.07, \mathrm{t}(7.9)$ & $4.07, \mathrm{~m}$ & $3.22, \mathrm{dd}(10.8,6.6)$ \\
\hline \multirow{2}{*}{7} & $2.39, \mathrm{~m}$ & $2.36, \mathrm{~m}$ & $2.31, \mathrm{~m}$ & $2.19, \mathrm{~m}$ & $2.35, \mathrm{dd}(13.5,6.4)$ & $2.32, \mathrm{~m}$ & $2.33, \mathrm{~m}$ & $2.25, \mathrm{dt}(12.0,6.6)$ \\
\hline & $1.93, \mathrm{~m}$ & $2.14, \mathrm{~m}$ & $2.02, \mathrm{~m}$ & $1.79, \mathrm{~m}$ & 2.06 , ddd $(13.5,11.2,4.3)$ & $1.94, \mathrm{~m}$ & $2.00, \mathrm{~m}$ & 1.84 , ddd $(12.0,10.8,7.5)$ \\
\hline \multirow{2}{*}{8} & $2.01, \mathrm{~m}$ & $2.02, \mathrm{~m}$ & $2.02, \mathrm{~m}$ & $1.94, \mathrm{~m}$ & & $2.07, \mathrm{~m}$ & $2.00, \mathrm{~m}$ & $1.96, \mathrm{~m}$ \\
\hline & $1.87, \mathrm{~m}$ & $1.89, \mathrm{~m}$ & $1.88, \mathrm{~m}$ & $1.69, \mathrm{~m}$ & $4.59, \mathrm{t}(4.3)$ & $.87, \mathrm{~m}$ & $1.89, \mathrm{~m}$ & $1.74, \mathrm{~m}$ \\
\hline \multirow{2}{*}{9} & $3.68, \mathrm{~m}$ & & $3.62, \mathrm{~m}$ & 3.62, ddd $(12.0,9.4,8.4)$ & $3.78, \mathrm{dd}(13.4,4.3)$ & $3.63, \mathrm{~m}$ & $3.62, \mathrm{dt}(11.5,8.0)$ & $3.64, \mathrm{dt}(11.9,8.4)$ \\
\hline & $3.50, \mathrm{~m}$ & $3.55, \mathrm{~m}$ & $3.59, \mathrm{~m}$ & 3.40 , ddd $(12.0,8.4,3.0)$ & $3.57, \mathrm{~d}(13.4)$ & $3.55, \mathrm{~m}$ & 3.55 , ddd $(11.5,9.0,2.4)$ & 3.42, ddd $(11.9,9.3,2.8)$ \\
\hline \multirow[t]{2}{*}{10} & $193 \mathrm{~m}$ & $250 \mathrm{~m} 236 \mathrm{~m}$ & $3.62, \mathrm{~m}$ & 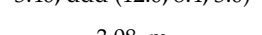 & $3.62, \mathrm{dd}(14.5,3.6)$ & $3.46, \mathrm{dd}(14.6,3.5)$ & 3.48 , dd $(14.8,3.3)$ & 3.01 dd $(14.0,7.0)$ \\
\hline & & & $2.76, \mathrm{dd}(14.5,10.5)$ & $3.08, \mathrm{~m}$ & $2.75, \mathrm{dd}(14.5,10.8)$ & $2.74, \mathrm{dd}(14.6,10.1)$ & $2.73, \mathrm{dd}(14.8,10.0)$ & $2.98, \mathrm{dd}(14.0,4.2)$ \\
\hline 11 & $\begin{array}{l}1.54, \mathrm{~m} \\
1.22 \mathrm{~m}\end{array}$ & $\begin{array}{l}3.02, \mathrm{~m} \\
2.79 \mathrm{~m}\end{array}$ & 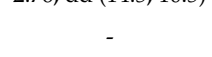 & - & 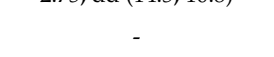 & - & - & - \\
\hline 12 & $0.91, \mathrm{t}(7.4)$ & $2.59, \mathrm{~s}$ & 7.20, br d $(7.2)$ & 7.19, br d $(7.2)$ & 7.21, br d $(7.4)$ & $7.03, \mathrm{~d}(8.6)$ & $7.18, \mathrm{~d}(2.0)$ & $7.17, \mathrm{~d}(2.0)$ \\
\hline 13 & $1.00, \mathrm{~d}(6.9)$ & & 7.33, brt (7.2) & 7.30, brt (7.2) & 7.34 , br t (7.4) & $6.76, \mathrm{~d}(8.6)$ & - & - \\
\hline 14 & & & 7.28, brt $(7.2)$ & 7.28, brt $(7.2)$ & 7.29, brt $(7.4)$ & - & - & - \\
\hline 15 & & & 7.33, brt $(7.2)$ & 7.30 , br t $(7.2)$ & 7.34, br t $(7.4)$ & $6.76, \mathrm{~d}(8.6)$ & $6.98, \mathrm{~d}(8.2)$ & $6.95, \mathrm{~d}(8.3)$ \\
\hline $\begin{array}{l}13 \\
16\end{array}$ & & & 7.20, br d (7.2) & 7.19 , br d (7.2) & 7.21 , br d (7.4) & $7.03, \mathrm{~d}(8.6)$ & $7.03, \mathrm{dd}(8.2,2.0)$ & $7.00, \mathrm{dd}(8.3,2.0)$ \\
\hline \multirow{2}{*}{17} & & & & & & & & \\
\hline \multirow{2}{*}{\multicolumn{9}{|c|}{$\begin{array}{l}18 \\
19\end{array}$}} \\
\hline & & & & & & & & \\
\hline \multicolumn{9}{|l|}{20} \\
\hline $\mathrm{OH}$ & & & & & & $6.69, \mathrm{br} \mathrm{s}$ & $5.55, \mathrm{br} \mathrm{s}$ & $5.53, \mathrm{br} \mathrm{s}$ \\
\hline
\end{tabular}

${ }^{1}$ In $\mathrm{CDCl}_{3}$ for 1-28 and 30-32 and in $\mathrm{CD}_{3} \mathrm{OD}$ for $29 .{ }^{2}$ Recorded at $400 \mathrm{MHz} .{ }^{3}$ Recorded at $950 \mathrm{MHz} .{ }^{4}$ Recorded at $700 \mathrm{MHz} .{ }^{5}$ Recorded at $600 \mathrm{MHz}$. 
Table 1. Cont

(c)

\begin{tabular}{|c|c|c|c|c|c|c|c|c|}
\hline Position & $17^{2}$ & $18^{4}$ & $19^{2}$ & $20^{5}$ & $21^{2}$ & $22^{5}$ & $23^{2}$ & $24^{5}$ \\
\hline 1 & - & $5.92, \mathrm{br} \mathrm{s}$ & 5.92 , br s & $5.88, \mathrm{br} \mathrm{s}$ & 6.27 , br s & $6.13, \mathrm{brs}$ & 5.97 , br s & $5.73, \mathrm{br} \mathrm{s}$ \\
\hline 3 & $4.36, \mathrm{dd}(10.9,3.0)$ & $\begin{array}{l}4.02, \mathrm{~d}(17.4) \\
3.98 \mathrm{~d}(17.4)\end{array}$ & $4.09, q(7.0)$ & $4.11, \mathrm{q}(7.0)$ & $3.89, \mathrm{br} \mathrm{s}$ & 3.97, br d $(9.9)$ & $3.94, \mathrm{br} \mathrm{s}$ & $4.00, q(7.0)$ \\
\hline 4 & 5.72, br s & $5.76, \mathrm{br} \mathrm{s}$ & $5.89, \mathrm{br} \mathrm{s}$ & $5.83, \mathrm{br} \mathrm{s}$ & $6.10, \mathrm{br} \mathrm{s}$ & $6.13, \mathrm{br} \mathrm{s}$ & $5.84, \mathrm{br} \mathrm{s}$ & $5.79, \mathrm{br} \mathrm{s}$ \\
\hline 6 & $4.06, t(8.0)$ & $\begin{array}{c}\text { 3.97, } \mathrm{m} \\
1.82, \operatorname{ddd}(13.3,9.6,\end{array}$ & $3.99, \mathrm{~m}$ & $3.95, \mathrm{br} \mathrm{s}$ & 4.00, br d (10.1) & 3.97, br d $(9.9)$ & 4.00, br d (10.2) & 4.26, br d $(8.2)$ \\
\hline 7 & $\begin{array}{l}2.31, \mathrm{~m} \\
2.00, \mathrm{~m}\end{array}$ & $\begin{array}{l}4.3) \\
1.66, \operatorname{ddd}(13.3,9.7, \\
4.5)\end{array}$ & $\begin{array}{l}1.89, \text { ddd }(13.9,9.5,3.8) \\
1.62, \text { ddd }(13.9,9.7,4.8)\end{array}$ & $2.12, \mathrm{~m}$ & $\begin{array}{c}1.88, \operatorname{ddd}(13.7,9.8,3.7) \\
1.60, \operatorname{ddd}(13.7,10.1,4.6)\end{array}$ & $\begin{array}{c}1.85, \operatorname{ddd}(13.4,9.6,3.7) \\
1.61, \mathrm{~m}\end{array}$ & $\begin{array}{c}1.89, \operatorname{ddd}(13.6,9.9,3.7) \\
1.60, \mathrm{~m}\end{array}$ & $\begin{array}{l}\text { 3.31, dd }(14.0,3.6) \\
\text { 3.00, dd }(14.0,8.2)\end{array}$ \\
\hline 8 & $\begin{array}{l}2.00, \mathrm{~m} \\
1.89, \mathrm{~m}\end{array}$ & $1.76, \mathrm{~m}$ & $1.75, \mathrm{~m}$ & $\begin{array}{l}1.46, \mathrm{~m} \\
1.25, \mathrm{~m}\end{array}$ & $1.76, \mathrm{~m}$ & $1.76, \mathrm{~m}$ & $1.76, \mathrm{~m}$ & - \\
\hline 9 & $3.60, \mathrm{~m}$ & $0.94, \mathrm{~d}(6.4)$ & $0.94, \mathrm{~d}(6.5)$ & $0.93, t(7.5)$ & $0.93, d(6.9)$ & $0.93, \mathrm{~d}(6.4)$ & $0.93, d(6.7)$ & 7.21, br d $(7.6)$ \\
\hline 10 & $\begin{array}{c}3.75, \mathrm{dd}(15.1,3.6) \\
2.95, \mathrm{dd}(15.1,10.9)\end{array}$ & $0.99, \mathrm{~d}(6.4)$ & $0.98, d(6.5)$ & $1.01, \mathrm{~d}(7.3)$ & $0.97, \mathrm{~d}(6.5)$ & $0.98, \mathrm{~d}(6.4)$ & $0.98, d(6.5)$ & 7.32 , br t $(7.6)$ \\
\hline 11 & - & & $1.50, \mathrm{~d}(7.0)$ & $1.50, \mathrm{~d}(7.0)$ & 2.41, qqd $(7.0,6.9,3.4)$ & $\begin{array}{c}1.85, \text { ddd }(13.4,9.6,3.7) \\
1.61, \mathrm{~m}\end{array}$ & $2.10, \mathrm{~m}$ & $7.28, \operatorname{brt}(7.6)$ \\
\hline 12 & $7.10, \mathrm{br} \mathrm{s}$ & & & & $0.93, \mathrm{~d}(6.9)$ & $1.76, \mathrm{~m}$ & $\begin{array}{l}1.45, \mathrm{~m} \\
1.22, \mathrm{~m}\end{array}$ & 7.32 , br t $(7.6)$ \\
\hline 13 & 8.20 , br s & & & & $1.03, d(7.0)$ & $0.93, \mathrm{~d}(6.4)$ & $0.92, \mathrm{t}(7.5)$ & 7.21, br d $(7.6)$ \\
\hline 14 & & & & & & $0.98, \mathrm{~d}(6.4)$ & $1.01, \mathrm{~d}(7.1)$ & $1.14, \mathrm{~d}(7.0)$ \\
\hline 15 & 7.38, br d $(8.0)$ & & & & & & & \\
\hline 16 & 7.22, brt $(8.0)$ & & & & & & & \\
\hline 17 & 7.13, br t $(8.0)$ & & & & & & & \\
\hline 18 & 7.57, br d $(8.0)$ & & & & & & & \\
\hline \multirow{2}{*}{\multicolumn{9}{|c|}{$\begin{array}{l}19 \\
20\end{array}$}} \\
\hline & & & & & & & & \\
\hline $\mathrm{OH}$ & & & & & & & & \\
\hline
\end{tabular}

${ }^{1}$ In $\mathrm{CDCl}_{3}$ for 1-28 and 30-32 and in $\mathrm{CD}_{3} \mathrm{OD}$ for $29 .{ }^{2}$ Recorded at $400 \mathrm{MHz} .{ }^{3}$ Recorded at $950 \mathrm{MHz} .{ }^{4}$ Recorded at $700 \mathrm{MHz} .{ }^{5}$ Recorded at $600 \mathrm{MHz}$. 
Table 1. Cont.

(d)

\begin{tabular}{|c|c|c|c|c|c|c|c|c|}
\hline Position & $25^{3}$ & $26^{2}$ & $27^{2}$ & $28^{5}$ & $29^{2}$ & $30^{4}$ & $31^{4}$ & $32^{5}$ \\
\hline 1 & 5.94, br s & $6.10, \mathrm{brs}$ & 5.79, br s & $5.78, \mathrm{br} \mathrm{s}$ & - & $5.65, \mathrm{brs}$ & $5.65, \mathrm{brs}$ & $5.79, \mathrm{br} \mathrm{s}$ \\
\hline 3 & $4.03, \mathrm{dd}(5.2,4.6)$ & $3.87, \mathrm{br} \mathrm{s}$ & 3.86, br d (10.2) & 3.91 , br s & $3.65, \mathrm{dd}(10.0,4.3)$ & $3.90, \mathrm{br} \mathrm{s}$ & $3.90, \mathrm{br} \mathrm{s}$ & 4.13, br d (8.5) \\
\hline 4 & $5.71, \mathrm{br} \mathrm{s}$ & $5.89, \mathrm{br} \mathrm{s}$ & 5.90, br s & $5.90, \mathrm{br} \mathrm{s}$ & 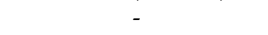 & $5.73, \mathrm{br} \mathrm{s}$ & $5.73, \mathrm{br} \mathrm{s}$ & 5.79, br s \\
\hline 6 & $4.25, \mathrm{dd}(8.9,3.6)$ & 4.22, br d $(9.7)$ & $4.26, \mathrm{dd}(7.9,3.9)$ & 4.22, br d $(9.6)$ & $4.23, \mathrm{dd}(4.6,3.6)$ & 4.15, br d $(9.4)$ & 4.19, br d $(8.9)$ & 4.13, br d (8.5) \\
\hline & $3.35, \mathrm{dd}(14.0,3.6)$ & $3.44, \mathrm{dd}(13.8,3.5)$ & $3.23, \mathrm{dd}(13.8,3.9)$ & $3.42, \mathrm{dd}(13.8,3.5)$ & $3.20, \mathrm{dd}(13.8,3.6)$ & $3.32, \mathrm{dd}(14.0,3.2)$ & $3.24, \mathrm{dd}(14.0,3.2)$ & 3.08, dd $(13.8,3.0$ \\
\hline 7 & $3.02, \mathrm{dd}(14.0,8.9)$ & $2.87, \mathrm{dd}(13.8,9.7)$ & 3.05 , dd $(13.8,7.9)$ & $2.89, \mathrm{dd}(13.8,9.6)$ & $2.82, \mathrm{dd}(13.8,4.6)$ & $2.83, \mathrm{dd}(14.0,9.4)$ & $2.89, \mathrm{dd}(14.0,8.9)$ & )2.30, dd $(13.8,8.5)$ \\
\hline 8 & & & & & & & & \\
\hline 9 & 7.20, br d (7.4) & 7.20, br d $(7.1)$ & 7.20, br d (7.3) & 7.20, br d $(7.1)$ & $6.99, \mathrm{~d}(8.5)$ & $7.07, \mathrm{~d}(8.4)$ & $7.17, \mathrm{br} \mathrm{s}$ & 7.11, br d (7.2) \\
\hline 10 & 7.34, br t $(7.4)$ & 7.33, br t $(7.1)$ & 7.33, brt $(7.3)$ & 7.33, brt $(7.1)$ & $6.71, \mathrm{~d}(8.5)$ & $6.79, \mathrm{~d}(8.4)$ & - & 7.34, br t (7.2) \\
\hline 11 & 7.29, br t (7.4) & 7.27, br t $(7.1)$ & 7.28, br t $(7.3)$ & 7.28, brt $(7.1)$ & - & - & - & 7.28, br t (7.2) \\
\hline 12 & $7.34, \operatorname{brt}(7.4)$ & $7.33, \operatorname{brt}(7.1)$ & $7.33, \operatorname{brt}(7.3)$ & $7.33, \operatorname{brt}(7.1)$ & $6.71, \mathrm{~d}(8.5)$ & $6.79, \mathrm{~d}(8.4)$ & $6.97, \mathrm{~d}(8.3)$ & 7.34, brt t(7.2) \\
\hline 13 & 7.20, br d $(7.4)$ & 7.20, br d (7.1) & 7.20, br d (7.3) & 7.20, br d (7.1) & $6.99, \mathrm{~d}(8.5)$ & $7.07, \mathrm{~d}(8.4)$ & 7.02, br d (8.3) & 7.11, br d $(7.2)$ \\
\hline 14 & $\begin{array}{l}3.65, \mathrm{dd}(11.0,4.6) \\
3.42, \mathrm{dd}(11.0,5.2)\end{array}$ & $\begin{array}{c}2.32, \mathrm{qqd}(7.0,7.0, \\
3.2)\end{array}$ & $\begin{array}{l}1.57, \mathrm{~m} \\
0.82, \mathrm{~m}\end{array}$ & $2.00, \mathrm{~m}$ & $\begin{array}{c}0.89, \mathrm{~m} \\
0.10, \operatorname{ddd}(14.7,10.0,4.9)\end{array}$ & $1.99, \mathrm{~m}$ & $1.99, \mathrm{~m}$ & $\begin{array}{l}\text { 3.08, dd }(13.8,3.0) \\
2.30, \mathrm{dd}(13.8,8.5)\end{array}$ \\
\hline 15 & & $0.80, \mathrm{~d}(7.0)$ & $1.49, \mathrm{~m}$ & $\begin{array}{l}1.26, \mathrm{~m} \\
1.05, \mathrm{~m}\end{array}$ & $1.44, \mathrm{~m}$ & $\begin{array}{l}1.19, \mathrm{~m} \\
1.00, \mathrm{~m}\end{array}$ & $\begin{array}{l}1.30, \mathrm{~m} \\
1.03, \mathrm{~m}\end{array}$ & - \\
\hline 16 & & $0.99, \mathrm{~d}(7.0)$ & $0.84, \mathrm{~d}(6.8)$ & $0.87, \mathrm{t}(7.4)$ & $0.73, \mathrm{~d}(6.7)$ & $0.85, t(7.5)$ & $0.87, \mathrm{t}(7.4)$ & 7.11, br d $(7.2)$ \\
\hline 17 & & & $0.85, \mathrm{~d}(6.8)$ & $0.96, \mathrm{~d}(7.1)$ & $0.75, \mathrm{~d}(6.7)$ & $0.94, \mathrm{~d}(7.2)$ & $0.96, \mathrm{~d}(7.2)$ & $7.34, \operatorname{brt}(7.2)$ \\
\hline 18 & & & & & & & & 7.28, br t (7.2) \\
\hline 19 & & & & & & & & 7.34, br t $(7.2)$ \\
\hline 20 & & & & & & & & 7.11, br d (7.2) \\
\hline $\mathrm{OH}$ & & & & & & & & \\
\hline
\end{tabular}

${ }^{1} \mathrm{In} \mathrm{CDCl}_{3}$ for 1-28 and 30-32 and in $\mathrm{CD}_{3} \mathrm{OD}$ for $\mathbf{2 9} .{ }^{2}$ Recorded at $400 \mathrm{MHz} .{ }^{3}$ Recorded at $950 \mathrm{MHz} .{ }^{4}$ Recorded at $700 \mathrm{MHz} .{ }^{5}$ Recorded at $600 \mathrm{MHz}$. 
Table 2. (a) ${ }^{13} \mathrm{C}$ NMR data $(\delta$ in ppm $){ }^{1}$ of compounds 1-16. (b) ${ }^{13} \mathrm{C}$ NMR data $(\delta \text { in ppm })^{1}$ of compounds 17-32.

\begin{tabular}{|c|c|c|c|c|c|c|c|c|c|c|c|c|c|c|c|c|}
\hline Position & $1^{2}$ & $2^{2}$ & $3^{3,4}$ & $4^{4}$ & $5^{2}$ & $6^{3,4}$ & $7^{2}$ & $8^{3,4}$ & $9^{2}$ & $10^{2}$ & $11^{3,4}$ & $12^{2}$ & $13^{2}$ & $14^{4}$ & $15^{3,5}$ & $16^{3,5}$ \\
\hline 2 & 163.3 & 166.2 & 165.7 & 166.1 & 166.4 & 167.4 & 167.7 & 165.1 & 165.3 & 165.2 & 165.0 & 164.8 & 166.2 & 165.3 & 164.7 & 164.4 \\
\hline 3 & 46.7 & 51.3 & 60.4 & 53.4 & 56.4 & 53.4 & 56.1 & 60.6 & 63.0 & 54.1 & 56.2 & 59.0 & 56.2 & 56.3 & 55.8 & 58.9 \\
\hline 5 & 169.5 & $\begin{array}{l}170.0 \\
\text { D }\end{array}$ & 170.1 & 170.2 & 169.6 & 170.0 & 169.8 & 169.9 & 169.4 & 170.2 & 169.4 & 169.3 & 169.8 & 169.7 & 169.1 & 168.4 \\
\hline 6 & 58.5 & 59.4 & 58.8 & 59.0 & 58.1 & 57.3 & 56.2 & 58.9 & 58.4 & 59.6 & 59.1 & 57.7 & 57.4 & 59.1 & 59.0 & 57.6 \\
\hline 7 & 28.5 & 28.2 & 28.6 & 28.1 & 29.1 & 37.8 & 36.8 & 28.6 & 29.5 & 28.2 & 28.3 & 28.9 & 37.7 & 28.2 & 28.2 & 28.7 \\
\hline 8 & 22.4 & 22.8 & 22.4 & 23.3 & 23.1 & 68.6 & 68.1 & 22.4 & 22.1 & 22.8 & 22.5 & 21.7 & 68.2 & 22.3 & 22.4 & 21.5 \\
\hline 9 & 45.4 & 45.5 & 45.2 & 45.5 & 45.7 & 54.5 & 54.0 & 45.2 & 45.7 & 45.5 & 45.5 & 45.1 & 54.4 & 45.3 & 45.3 & 45.1 \\
\hline 10 & & 16.2 & 28.4 & 38.6 & 42.6 & 38.5 & 42.2 & 35.3 & 39.7 & 23.2 & 36.8 & 40.5 & 36.7 & 35.9 & 35.5 & 39.2 \\
\hline 11 & & & 16.1 & 24.7 & 24.5 & 24.9 & 24.6 & 24.1 & 24.6 & 49.4 & 135.9 & 135.3 & 135.8 & 126.5 & 128.8 & 128.4 \\
\hline 12 & & & 19.2 & 21.2 & 21.4 & 21.7 & 21.5 & 12.2 & 11.4 & 38.5 & 129.3 & 129.9 & 129.3 & 130.4 & 129.3 & 129.7 \\
\hline 13 & & & & 22.7 & 22.3 & 23.6 & 23.0 & 16.0 & 15.4 & & 129.1 & 128.8 & 129.2 & 116.0 & 120.2 & 120.0 \\
\hline 14 & & & & & & & & & & & 127.6 & 127.3 & 127.6 & 155.9 & 150.6 & 150.8 \\
\hline 15 & & & & & & & & & & & 129.1 & 128.8 & 129.2 & 116.0 & 116.7 & 116.3 \\
\hline 16 & & & & & & & & & & & 129.3 & 129.9 & 129.3 & 130.4 & 129.0 & 129.5 \\
\hline
\end{tabular}

${ }^{1}$ In $\mathrm{CDCl}_{3}$ for 1-28 and 30-32 and in $\mathrm{CD}_{3} \mathrm{OD}$ for 29. ${ }^{2}$ Adapted (and revised when appropriate) as follows: $\mathbf{1}$ [25], 2 [27], 5 [31], 7 [35], 9 [37], 10 [38], 12 [40], 13 [41], 17 [44], 21 [37], 23 [17], 27 [17], 29 [54]. ${ }^{3}$ Determined through HMBC correlations. ${ }^{4}$ Recorded at $100 \mathrm{MHz} .{ }^{5}$ Recorded at $237.5 \mathrm{MHz} .{ }^{6}$ Recorded at $175 \mathrm{MHz} .{ }^{7}$ Recorded at $150 \mathrm{MHz} .{ }^{8}$ nd: not detected.

\begin{tabular}{|c|c|c|c|c|c|c|c|c|c|c|c|c|c|c|c|c|}
\hline & & & & & & & & (b & & & & & & & & \\
\hline Position & $17^{2}$ & $18^{3,6}$ & $19^{3,4}$ & $20^{3,7}$ & $21^{2}$ & $22^{3,7}$ & $23^{2}$ & $24^{3,7}$ & $25^{3,5}$ & $26^{3,4}$ & $27^{2}$ & $28^{3,7}$ & $29^{2}$ & $30^{3,6}$ & $31^{3,6}$ & $32^{3,7}$ \\
\hline 2 & 165.7 & 165.3 & nd $^{8}$ & $\mathrm{nd}^{8}$ & 167.4 & $\mathrm{nd}^{8}$ & 167.3 & $\mathrm{nd}^{8}$ & $\mathrm{nd}^{8}$ & $\mathrm{nd}^{8}$ & 167.6 & $\mathrm{nd}^{8}$ & 167.6 & 166.1 & 166.2 & $\mathrm{nd}^{8}$ \\
\hline 3 & 54.7 & 44.6 & 51.1 & 50.6 & 60.3 & 53.0 & 60.1 & 50.7 & 55.8 & 60.4 & 53.4 & 59.8 & 52.8 & 59.9 & 59.9 & 56.1 \\
\hline 5 & 169.5 & 168.1 & $\mathrm{nd}^{8}$ & $\mathrm{nd}^{8}$ & 169.0 & nd $^{8}$ & 168.8 & nd $^{8}$ & nd $^{8}$ & $\mathrm{nd}^{8}$ & 167.8 & $\mathrm{nd}^{8}$ & 171.4 & $\mathrm{nd}^{8}$ & $\mathrm{nd}^{8}$ & $n^{8} d^{8}$ \\
\hline 6 & 59.3 & 53.2 & 53.7 & 60.0 & 53.2 & 53.0 & 53.2 & 56.2 & 55.8 & 56.5 & 56.4 & 55.9 & 56.3 & 55.8 & 55.9 & 56.1 \\
\hline 7 & 28.4 & 42.3 & 42.7 & 37.7 & 43.9 & 42.7 & 43.6 & 39.8 & 39.8 & 41.0 & 40.2 & 40.2 & 38.1 & 39.3 & 38.9 & 40.1 \\
\hline 8 & 22.7 & 24.0 & 25.2 & 23.6 & 24.3 & 24.3 & 24.1 & 135.3 & 134.9 & 135.4 & 135.1 & 135.6 & 125.7 & 127.3 & 128.2 & 135.3 \\
\hline 9 & 45.5 & 21.0 & 21.7 & 11.5 & 21.1 & 20.8 & 21.2 & 129.6 & 129.3 & 129.6 & 130.2 & 129.3 & 131.4 & 130.6 & 129.7 & 129.5 \\
\hline 10 & 26.9 & 22.8 & 23.6 & 15.0 & 23.4 & 23.0 & 23.5 & 128.8 & 128.9 & 129.0 & 129.2 & 128.9 & 115.1 & 115.7 & 120.1 & 128.7 \\
\hline 11 & 109.3 & & 20.4 & 20.5 & 31.6 & 42.7 & 38.3 & 127.5 & 127.4 & 127.7 & 127.8 & 127.3 & 157.0 & 155.0 & 150.4 & 127.4 \\
\hline 12 & 123.6 & & & & 16.5 & 24.3 & 24.4 & 128.8 & 128.9 & 129.0 & 129.2 & 128.9 & 115.1 & 115.7 & 116.6 & 128.7 \\
\hline 13 & - & & & & 18.9 & 20.8 & 11.9 & 129.6 & 129.3 & 129.6 & 130.2 & 129.3 & 131.4 & 130.6 & 129.5 & 129.5 \\
\hline 14 & 136.8 & & & & & 23.0 & 15.4 & 19.8 & 63.7 & 31.6 & 43.1 & 37.9 & 43.9 & 37.8 & 37.8 & 40.1 \\
\hline 15 & 111.7 & & & & & & & & & 16.4 & 23.2 & 23.3 & 23.3 & 23.3 & 23.1 & 135.3 \\
\hline 16 & 122.8 & & & & & & & & & 19.3 & 20.9 & 11.3 & 20.0 & 11.5 & 11.5 & 129.5 \\
\hline 17 & 120.0 & & & & & & & & & & 22.8 & 15.1 & 22.1 & 15.1 & 15.1 & 128.7 \\
\hline 18 & 118.6 & & & & & & & & & & & & & & & 127.4 \\
\hline 19 & 126.8 & & & & & & & & & & & & & & & 128.7 \\
\hline 20 & & & & & & & & & & & & & & & & 129.5 \\
\hline
\end{tabular}

${ }^{1}$ In $\mathrm{CDCl}_{3}$ for 1-28 and $\mathbf{3 0 - 3 2}$ and in $\mathrm{CD}_{3} \mathrm{OD}$ for 29. ${ }^{2}$ Adapted (and revised when appropriate) as follows: $\mathbf{1}$ [25], 2 [27], 5 [31], 7 [35], 9 [37], 10 [38], 12 [40], 13 [41], 17 [44], 21 [37], 23 [17], 27 [17], 29 [54]. ${ }^{3}$ Determined through HMBC correlations. ${ }^{4}$ Recorded at $100 \mathrm{MHz} .{ }^{5}$ Recorded at $237.5 \mathrm{MHz} .{ }^{6}$ Recorded at $175 \mathrm{MHz} .{ }^{7}$ Recorded at $150 \mathrm{MHz} .{ }^{8}$ nd: not detected. 


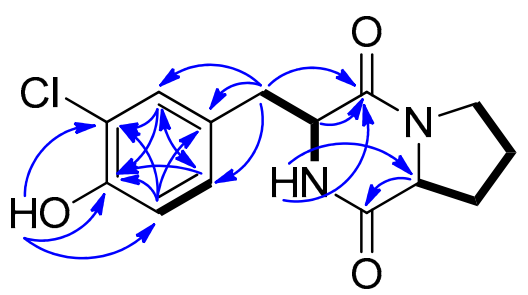

$15 / 16$

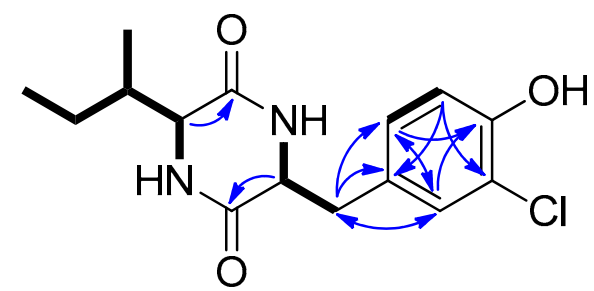

31

Figure 3. COSY (bold bonds) and important HMBC (arrows) correlations observed for compounds 15/16 and 31.

Compounds 15 and 16 were evaluated for their antifungal activity against Candida albicans and Aspergillus niger. However, neither of the two metabolites exerted any significant effect on the growth of the two fungal strains.

\section{Materials and Methods}

\subsection{General Experimental Procedures}

Optical rotations were measured on a Krüss model P3000 polarimeter (A. KRÜSS Optronic $\mathrm{GmbH}$, Hamburg, Germany) with a $0.5 \mathrm{dm}$ cell. UV spectra were obtained on a Perkin Elmer Lambda 40 spectrophotometer (PerkinElmer Ltd., Buckinghamshire, UK). IR spectra were obtained on a Bruker Alpha II spectrometer (Bruker Optik GmbH, Ettlingen, Germany). 1D and 2D NMR spectra were recorded on Bruker DRX 400, Avance NEO 700 and Avance NEO 950 (Bruker BioSpin $\mathrm{GmbH}$, Rheinstetten, Germany) and Varian 600 (Varian, Inc., Palo Alto, CA, USA), spectrometers, using standard Bruker or Varian pulse sequences at room temperature. Chemical shifts are given on a $\delta(\mathrm{ppm})$ scale using TMS as internal standard. High-resolution electrospray ionization (ESI) mass spectra were measured on a Thermo Scientific LTQ Orbitrap Velos mass spectrometer (Thermo Fisher Scientific, Bremen, Germany). Low-resolution electron ionization (EI) mass spectra were measured on a Hewlett-Packard 5973 mass spectrometer (Agilent Technologies, Santa Clara, CA, USA) or on a Thermo Electron Corporation DSQ mass spectrometer (Thermo Electron Corporation, Austin, TX, USA). Normal- and reversed-phase column chromatography separations were performed with Kieselgel $\mathrm{Si}$ 60 (Merck, Darmstadt, Germany) and Kieselgel RP-18 (Merck, Darmstadt, Germany), respectively. HPLC separations were conducted on (i) a Cecil 1100 Series liquid chromatography pump (Cecil Instruments Ltd., Cambridge, UK) equipped with a GBC LC-1240 refractive index detector (GBC Scientific Equipment, Braeside, VIC, Australia), (ii) a Pharmacia LKB 2248 liquid chromatography pump (Pharmacia LKB Biotechnology, Uppsala, Sweden) equipped with an RI-102 Shodex refractive index detector (ECOM spol. s r.o., Prague, Czech Republic), (iii) an Agilent 1100 liquid chromatography system equipped with refractive index detector (Agilent Technologies, Waldbronn, Germany), (iv) a Waters 600 liquid chromatography pump (Waters, Milford, MA, USA) with a Waters 410 refractive index detector (Waters, Milford, MA, USA), or (v) a Waters 515 liquid chromatography pump (Waters, Milford, MA, USA) equipped with a Shimadzu RID-20A refractive index detector (Shimadzu Europa $\mathrm{GmbH}$, Duisburg, Germany), using the following columns: (i) Econosphere $\mathrm{C}_{18} 10 \mathrm{u}(250 \times 10 \mathrm{~mm}$, Grace, Columbia, MD, USA), (ii) Kromasil 100-7- $\mathrm{C}_{18}(250 \times 10 \mathrm{~mm}$, Akzonobel, Eka Chemicals AB, Separation Products, Bohus, Sweden), (iii) Luna $\mathrm{C}_{18}$ (2) $100 \mathrm{~A} 10 \mathrm{u}(250 \times 10 \mathrm{~mm}$, Phenomenex, Torrance, CA, USA), (iv) Econosphere Silica 10u ( $250 \times 10$ mm, Grace, Columbia, MD, USA), (v) Kromasil 100-10-SIL ( $250 \times 10$ mm, Akzonobel, Eka Chemicals AB, Separation Products, Bohus, Sweden), or (vi) Supelcosil SPLC-Si $5 \mu \mathrm{m}(250 \times 10 \mathrm{~mm}$, Supelco, Bellefonte, PA, USA). TLC was performed with Kieselgel $60 \mathrm{~F}_{254}$ aluminum-backed plates (Merck, Darmstadt, Germany) and spots were visualized after spraying with $15 \%(\mathrm{v} / \mathrm{v}) \mathrm{H}_{2} \mathrm{SO}_{4}$ in $\mathrm{MeOH}$ reagent and heating at $100{ }^{\circ} \mathrm{C}$ for $1 \mathrm{~min}$. 


\subsection{Biological Material}

The bacterial strains were isolated from marine sediments collected from the East Mediterranean Sea and were identified based on comparison of their 16S ribosomal RNA (rRNA) sequences with data from the Genbank database of the National Center for Biotechnology Information (NCBI) using the Basic Local Alignment Search Tool (BLAST). Specifically, strain BI0327, identified as Bacillus endophyticus (GenBank accession number DQ485415), was isolated from a sediment collected east of Thiorichio in the island of Milos, at a depth of $4 \mathrm{~m}$, in July 2012. Strain BI0383, identified as Streptomyces albidoflavus (GenBank accession number KJ573071), was isolated from a sediment collected east of Loutra in the island of Kythnos, at a depth of 150 m, in March 2013. Strain BI0618, identified as Nocardiopsis aegyptia (GenBank accession number NR_025589), was isolated from a sediment collected west of Agios Ioannis, in the island of Lemnos, at a depth of $6 \mathrm{~m}$, in October 2013. Strain BI0918, identified as Streptomyces smyrnaeus (GenBank accession number NR_134201), was isolated from a sediment collected south of Vatsa, in the island of Kefalonia, at a depth of 75 m, in May 2014. Strain BI0980, identified as Bacillus subtilis (GenBank accession number JN560160), was isolated from a sediment collected in the waters between the islands of Kerkyra and Erikoussa, at a depth of 18 m, in August 2014. The strains have been deposited at the strain collection/microbank of the Section of Pharmacognosy and Chemistry of Natural Products, Department of Pharmacy, National and Kapodistrian University of Athens.

\subsection{Fermentation, Extraction, and Isolation}

The bacterial strain BI0327 was inoculated from a glycerol stock into a 1 L flask containing $500 \mathrm{~mL}$ of freshly prepared seawater-based $(\mathrm{A} 1 \mathrm{BFe}+\mathrm{C})$ medium $(10 \mathrm{~g}$ starch, $4 \mathrm{~g}$ yeast extract, $2 \mathrm{~g}$ peptone, $1 \mathrm{~g} \mathrm{CaCO}_{3}, 0.1 \mathrm{~g} \mathrm{KBr}$, and $0.04 \mathrm{~g} \mathrm{Fe}_{2}(\mathrm{SO} 4)_{3} 5 \mathrm{H}_{2} \mathrm{O}$ per liter of filtered seawater) [56]. After 7 days of incubation at $28{ }^{\circ} \mathrm{C}$, while shaking at $120 \mathrm{rpm}$ in an orbit shaker, the starter cultures were inoculated into $3 \mathrm{~L}$ flasks containing $1.5 \mathrm{~L}$ of the same seawater-based medium ( $4 \% v / v$ inoculum), to a total of 12 $\mathrm{L}$ of liquid medium, which were incubated at $28{ }^{\circ} \mathrm{C}$ for 14 days, while shaking at $120 \mathrm{rpm}$ in an orbit shaker. Four days before the end of the fermentation period, Amberlite XAD-7HP resin (Sigma-Aldrich, St. Louis, MO, USA) (20 g/L) was added to each flask to adsorb extracellular metabolites. The broth was centrifuged and the pellet (resin and cell mass), was extracted twice for $24 \mathrm{~h}$ with $\mathrm{Me}_{2} \mathrm{CO}(8$ $\mathrm{L}$ in total). Filtration of the extract and removal of the solvent under vacuum at $38{ }^{\circ} \mathrm{C}$ afforded a solid residue, which was partitioned between $n$-butanol and $\mathrm{H}_{2} \mathrm{O}$. Evaporation of the solvent of the $n$-butanol soluble fraction in vacuo afforded a dark brown oily residue ( $2.2 \mathrm{~g})$ that was subjected to vacuum column chromatography on silica gel, using cyclohexane, with increasing amounts of EtOAc, followed by EtOAc, with increasing amounts of $\mathrm{MeOH}$ as the mobile phase, to afford 8 fractions (327A-327H). Fraction 327G (50\% MeOH in EtOAc, $1.1 \mathrm{~g}$ ) was further fractionated by gravity column chromatography on silica gel, using EtOAc with increasing amounts of $\mathrm{MeOH}$ as the mobile phase, to yield 26 fractions (327G1-327G26). Fractions 327G10 to 327G15 (2\% to 10\% MeOH in EtOAc, $110.0 \mathrm{mg}$ ) were combined and purified by reversed-phase $\mathrm{HPLC}$, using $\mathrm{MeOH} / \mathrm{H}_{2} \mathrm{O}(70: 30$ and subsequently 50:50) and $\mathrm{MeCN} / \mathrm{H}_{2} \mathrm{O}(30: 70)$ as eluent, to afford 3 (3.9 mg), $4(2.4 \mathrm{mg}), 5(1.7 \mathrm{mg}), 6(8.3 \mathrm{mg}), 8(6.6 \mathrm{mg})$, $\mathbf{1 1}(7.3 \mathrm{mg}), \mathbf{1 3}(6.1 \mathrm{mg})$, and $\mathbf{1 7}(1.2 \mathrm{mg})$. Fractions 327G16 (10\% MeOH in EtOAc, $29.7 \mathrm{mg})$ and $327 \mathrm{G} 17$ $\left(10 \% \mathrm{MeOH}\right.$ in EtOAc, $26.3 \mathrm{mg}$ ) were separately purified by reversed-phase HPLC, using $\mathrm{MeOH} / \mathrm{H}_{2} \mathrm{O}$ (50:50) as eluent, and subsequently normal-phase HPLC, using cyclohexane/ $\mathrm{Me}_{2} \mathrm{CO}(20: 80)$ as eluent, to yield 7 (2.7 $\mathrm{mg})$ and $13(6.1 \mathrm{mg})$.

The bacterial strain BI0383 was inoculated from a glycerol stock into a $100 \mathrm{~mL}$ flask containing $50 \mathrm{~mL}$ of freshly prepared seawater-based $(\mathrm{A} 1 \mathrm{BFe}+\mathrm{C})$ medium. After 4 days of incubation at $24^{\circ} \mathrm{C}$ while shaking at $125 \mathrm{rpm}$ in an orbit shaker, the starter culture was streaked onto 18 freshly prepared agar plates containing the same seawater-based medium. After 7 days, when sufficient growth of the bacterial strain was observed, mycelia were picked from the agar plates and were inoculated into $2 \mathrm{~L}$ flasks containing $1 \mathrm{~L}$ of the same seawater-based medium, to a total of $6 \mathrm{~L}$ of liquid medium, that were incubated at $27^{\circ} \mathrm{C}$ for 7 days while shaking at $125 \mathrm{rpm}$ in an orbit shaker. At the end of the fermentation period, Amberlite XAD-7HP resin $(20 \mathrm{~g} / \mathrm{L})$ was added to each flask to adsorb extracellular 
metabolites. The culture and resin were shaken overnight at low speed. The broth was centrifuged and the pellet (resin and cell mass) was extracted twice for $24 \mathrm{~h}$ with $\mathrm{Me}_{2} \mathrm{CO}(4 \mathrm{~L}$ in total). Filtration of the extract and removal of the solvent under vacuum at $38{ }^{\circ} \mathrm{C}$ afforded a solid residue, which was partitioned between $n$-butanol and $\mathrm{H}_{2} \mathrm{O}$. Evaporation of the solvent of the $n$-butanol soluble fraction in vacuo afforded a brown oily residue $(2.22 \mathrm{~g})$ that was subjected to vacuum column chromatography on silica gel, using cyclohexane with increasing amounts of EtOAc, followed by EtOAc with increasing amounts of $\mathrm{MeOH}$ as the mobile phase, to yield 12 fractions (383A-383L). Fraction 383K $(10 \% \mathrm{MeOH}$ in EtOAc, $54.0 \mathrm{mg}$ ) was submitted to normal-phase HPLC, using cyclohexane/ $\mathrm{Me}_{2} \mathrm{CO}(55: 45)$ as eluent, to afford $4(6.0 \mathrm{mg}), 3(0.4 \mathrm{mg})$, and $8(0.9 \mathrm{mg})$. The soluble in $80 \% \mathrm{MeOH}$ in $\mathrm{H}_{2} \mathrm{O}$ part $(111.0 \mathrm{mg})$ of fraction 383L (25\% MeOH in EtOAc) was purified by reversed-phase HPLC, using $\mathrm{MeCN} / \mathrm{H}_{2} \mathrm{O}$ (10:90) as eluent, to yield $\mathbf{1}(10.0 \mathrm{mg})$. The soluble in $50 \% \mathrm{MeOH}$ in $\mathrm{H}_{2} \mathrm{O}$ part $(77.0 \mathrm{mg})$ of fraction $383 \mathrm{~L}$ was purified by reversed-phase HPLC, using $\mathrm{MeCN} / \mathrm{H}_{2} \mathrm{O}(40: 60)$ as eluent, to yield $6(1.7 \mathrm{mg})$ and 13 (1.1 mg).

The bacterial strain BI0618 was streaked from a glycerol stock onto 25 freshly prepared agar plates containing a seawater-based $(\mathrm{A} 1 \mathrm{BFe}+\mathrm{C})$ medium. After 3 days, when sufficient growth of the bacterial strain was observed, mycelia were picked from the agar plates and were inoculated into $1 \mathrm{~L}$ flasks containing $400 \mathrm{~mL}$ of the same seawater-based medium, to a total of $10 \mathrm{~L}$ of liquid medium, which were incubated at $24^{\circ} \mathrm{C}$ for 8 days, while shaking at $130 \mathrm{rpm}$ in an orbit shaker. At the end of the fermentation period, Amberlite XAD-7HP resin $(20 \mathrm{~g} / \mathrm{L})$ was added to each flask to adsorb extracellular metabolites. The culture and resin were shaken overnight at low speed. The broth was centrifuged and the pellet (resin and cell mass) was extracted twice for $24 \mathrm{~h}$ with $\mathrm{Me}_{2} \mathrm{CO}(8 \mathrm{~L}$ in total). Filtration of the extract and removal of the solvent under vacuum at $38{ }^{\circ} \mathrm{C}$ afforded a solid residue, which was partitioned between EtOAc and $\mathrm{H}_{2} \mathrm{O}$. Evaporation of the solvent of the EtOAc soluble fraction in vacuo afforded a dark orange oily residue $(498 \mathrm{mg})$ that was subjected to vacuum column chromatography on silica gel, using cyclohexane, with increasing amounts of EtOAc, followed by EtOAc with increasing amounts of $\mathrm{MeOH}$ as the mobile phase, to yield 12 fractions (618A-618L). Fraction 618F (100\% EtOAc, $8.4 \mathrm{mg}$ ) was identified as compound 4. Fraction 618G (5\% MeOH in EtOAc, $40.1 \mathrm{mg})$ was subjected to normal-phase HPLC, using cyclohexane/ $\mathrm{Me}_{2} \mathrm{CO}(55: 45)$ as eluent, to afford compounds 4 (6.1 mg) and 8 (5.3 mg). Fraction $618 \mathrm{H}(20 \% \mathrm{MeOH}$ in EtOAc, $140.1 \mathrm{mg})$ was subjected to vacuum column chromatography on silica gel, using cyclohexane with increasing amounts of $\mathrm{Me}_{2} \mathrm{CO}$, followed by $\mathrm{Me}_{2} \mathrm{CO}$ with increasing amounts of $\mathrm{MeOH}$ as the mobile phase, to afford 10 fractions $(618 \mathrm{H} 1-618 \mathrm{H} 10)$. The soluble in $80 \% \mathrm{MeOH}$ in $\mathrm{H}_{2} \mathrm{O}$ part $(27.0 \mathrm{mg})$ of fraction $618 \mathrm{H} 2\left(60 \% \mathrm{Me}_{2} \mathrm{CO}\right.$ in cyclohexane) was purified by reversed-phase HPLC, using $\mathrm{MeOH} / \mathrm{H}_{2} \mathrm{O}(60: 40$ and subsequently 50:50) as eluent, to yield 5 (0.3 mg), 11 (4.5 mg), 12 (0.4 mg), 14 (4.4 mg), 21 (1.1 mg), 26 (1.3 mg), 27 (0.9 mg), 28 (1.1 mg), and 32 (1.0 mg).

The bacterial strain BI0918 was inoculated from a glycerol stock into a $100 \mathrm{~mL}$ flask containing $50 \mathrm{~mL}$ of freshly prepared seawater-based $(\mathrm{A} 1 \mathrm{BFe}+\mathrm{C})$ medium. After 4 days of incubation at $24^{\circ} \mathrm{C}$, while shaking at $120 \mathrm{rpm}$ in an orbit shaker, the starter culture was streaked onto 25 freshly prepared agar plates containing the same seawater-based medium. After 7 days when sufficient growth of the bacterial strain was observed, mycelia were picked from the agar plates and were inoculated into $1 \mathrm{~L}$ flasks containing $400 \mathrm{~mL}$ of the same seawater-based medium, to a total of $20 \mathrm{~L}$ of liquid medium, which were incubated at $24{ }^{\circ} \mathrm{C}$ for 8 days, while shaking at $120 \mathrm{rpm}$ in an orbit shaker. At the end of the fermentation period, Amberlite XAD-7HP resin $(20 \mathrm{~g} / \mathrm{L})$ was added to each flask to adsorb extracellular metabolites. The culture and resin were shaken overnight at low speed. The broth was centrifuged and the pellet (resin and cell mass) was extracted twice for $24 \mathrm{~h}$ with $\mathrm{Me}_{2} \mathrm{CO}(12 \mathrm{~L}$ in total). Filtration of the extract and removal of the solvent under vacuum at $38{ }^{\circ} \mathrm{C}$ afforded a solid residue, which was partitioned between EtOAc and $\mathrm{H}_{2} \mathrm{O}$. Evaporation of the solvent of the EtOAc soluble fraction in vacuo afforded a dark red oily residue $(2.0 \mathrm{~g})$ that was subjected to vacuum column chromatography on silica gel, using cyclohexane with increasing amounts of EtOAc, followed by EtOAc with increasing amounts of $\mathrm{MeOH}$ as the mobile phase, to yield 14 fractions (918A-918N). 
Fractions 918G (70\% EtOAc in cyclohexane, $45.8 \mathrm{mg}), 918 \mathrm{H}$ (80\% EtOAc in cyclohexane, $52.0 \mathrm{mg}$ ), 918I (90\% EtOAc in cyclohexane, $10.5 \mathrm{mg})$, and 918J (100\% EtOAc and 5\% MeOH in EtOAc, $59.8 \mathrm{mg})$ were separately purified by normal-phase HPLC, using cyclohexane/ $\mathrm{Me}_{2} \mathrm{CO}$ (70:30 and/or 65:35) as eluent, to yield $4(20.2 \mathrm{mg})$. Fraction $918 \mathrm{~K}(10 \% \mathrm{MeOH}$ in EtOAc, $114.7 \mathrm{mg})$ was further fractionated by vacuum column chromatography on silica gel C-18, using $\mathrm{H}_{2} \mathrm{O}$ with increasing amounts of $\mathrm{MeOH}$ as the mobile phase, to afford 5 fractions (918K1-918K5). Fractions 918K1 (20\% $\mathrm{MeOH}$ in $\left.\mathrm{H}_{2} \mathrm{O}, 41.5 \mathrm{mg}\right)$ and $918 \mathrm{~K} 2\left(40 \% \mathrm{MeOH}\right.$ in $\left.\mathrm{H}_{2} \mathrm{O}, 28.1 \mathrm{mg}\right)$ were separately purified by reversed-phase HPLC, using $\mathrm{MeOH} / \mathrm{H}_{2} \mathrm{O}$ (30:70) and subsequently $\mathrm{MeCN} / \mathrm{H}_{2} \mathrm{O}$ (30:70) as eluent, to yield 3 (7.0 mg), 4 (7.3 mg), 5 (2.0 mg), 8 (13.5 mg), and $11(0.3 \mathrm{mg})$. Fraction $918 \mathrm{~K} 3\left(60 \% \mathrm{MeOH}\right.$ in $\left.\mathrm{H}_{2} \mathrm{O}, 14.4 \mathrm{mg}\right)$ was purified by reversed-phase $\mathrm{HPLC}$, using $\mathrm{MeOH} / \mathrm{H}_{2} \mathrm{O}$ (50:50) as eluent, to yield 21 (1.1 mg), 22 (5.4 mg), and 23 (1.3 mg). Fraction 918L ( $25 \% \mathrm{MeOH}$ in EtOAc, $113.5 \mathrm{mg}$ ) was further fractionated by vacuum column chromatography on silica gel C-18, using $\mathrm{H}_{2} \mathrm{O}$ with increasing amounts of $\mathrm{MeOH}$ as the mobile phase, to afford 5 fractions (918L1-918L5). Fraction 918L1 (20\% MeOH in $\left.\mathrm{H}_{2} \mathrm{O}, 22.3 \mathrm{mg}\right)$ was purified by reversed-phase $\mathrm{HPLC}$, using $\mathrm{MeOH} / \mathrm{H}_{2} \mathrm{O}$ (30:70 and subsequently 25:75) as eluent, to yield 2 (0.5 mg), $14(4.7 \mathrm{mg}), 16(0.4 \mathrm{mg})$, and $18(0.4 \mathrm{mg})$. Fraction 918L2 (40\% $\mathrm{MeOH}$ in $\left.\mathrm{H}_{2} \mathrm{O}, 42.9 \mathrm{mg}\right)$ was purified by reversed-phase $\mathrm{HPLC}$, using $\mathrm{MeOH} / \mathrm{H}_{2} \mathrm{O}$ (50:50) and subsequently $\mathrm{MeCN} / \mathrm{H}_{2} \mathrm{O}$ (30:70) as eluent, and finally normal-phase HPLC, using cyclohexane/ $\mathrm{Me}_{2} \mathrm{CO}$ (20:80) as eluent, to yield $\mathbf{5}(1.1 \mathrm{mg}), \mathbf{9}(0.9 \mathrm{mg})$, $\mathbf{1 1}$ (10.9 mg), 12 (3.3 mg), $\mathbf{1 4}(2.0 \mathrm{mg}), \mathbf{1 7}(2.0 \mathrm{mg}), \mathbf{1 9}(0.5 \mathrm{mg}), \mathbf{2 0}$ (1.1 mg), $2 \mathbf{1}(0.6 \mathrm{mg})$, and $\mathbf{2 6}$ (2.2 mg). Fraction 918L3 $\left(60 \% \mathrm{MeOH}\right.$ in $\left.\mathrm{H}_{2} \mathrm{O}, 10.7 \mathrm{mg}\right)$ was purified by reversed-phase $\mathrm{HPLC}$, using $\mathrm{MeOH} / \mathrm{H}_{2} \mathrm{O}$ (50:50) as eluent and subsequently normal-phase HPLC, using cyclohexane/ $\mathrm{Me}_{2} \mathrm{CO}(30: 70)$ as eluent, to yield $26(2.0 \mathrm{mg}), 27(2.0 \mathrm{mg}), 28(2.0 \mathrm{mg})$, and $32(2.4 \mathrm{mg})$. Fractions $918 \mathrm{M}(100 \% \mathrm{MeOH}, 464.0 \mathrm{mg})$ and $918 \mathrm{~N}(100 \% \mathrm{MeOH}, 23.0 \mathrm{mg})$ were combined and fractionated by vacuum column chromatography on silica gel C-18, using $\mathrm{H}_{2} \mathrm{O}$ with increasing amounts of $\mathrm{MeOH}$ as the mobile phase, to afford 5 fractions (918M1-918M5). Fractions 918M1 (20\% MeOH in $\left.\mathrm{H}_{2} \mathrm{O}, 186.2 \mathrm{mg}\right), 918 \mathrm{M} 2$ (40\% $\mathrm{MeOH}$ in $\left.\mathrm{H}_{2} \mathrm{O}, 30.9 \mathrm{mg}\right)$, and $918 \mathrm{M} 3\left(60 \% \mathrm{MeOH}\right.$ in $\left.\mathrm{H}_{2} \mathrm{O}, 12.9 \mathrm{mg}\right)$ were separately and repeatedly purified by reversed-phase $\mathrm{HPLC}$, using $\mathrm{MeOH} / \mathrm{H}_{2} \mathrm{O}$ (40:60 and subsequently 25:75) as eluent, to yield $\mathbf{1 0}(0.5 \mathrm{mg})$ and $24(4.1 \mathrm{mg})$.

The bacterial strain BI0980 was inoculated from a glycerol stock into two $100 \mathrm{~mL}$ flasks containing $50 \mathrm{~mL}$ of freshly prepared seawater-based $(\mathrm{A} 1 \mathrm{BFe}+\mathrm{C})$ medium. After 5 days of incubation at $24{ }^{\circ} \mathrm{C}$ while shaking at $120 \mathrm{rpm}$ in an orbit shaker, the starter cultures were inoculated into two $1 \mathrm{~L}$ flasks containing $500 \mathrm{~mL}$ of the same seawater-based medium (10\% $v / v$ inoculum) that were incubated at $24{ }^{\circ} \mathrm{C}$ for 4 days, while shaking at $120 \mathrm{rpm}$ in an orbit shaker. Subsequently, they were inoculated into $1 \mathrm{~L}$ flasks containing $500 \mathrm{~mL}$ of the same seawater-based medium ( $10 \% v / v$ inoculum), to a total of $10 \mathrm{~L}$ of liquid medium, that were incubated at $24{ }^{\circ} \mathrm{C}$ for 9 days while shaking at $120 \mathrm{rpm}$ in an orbit shaker. At the end of the fermentation period, Amberlite XAD-7HP resin (20 g/L) was added to each flask to adsorb extracellular metabolites. The culture and resin were shaken overnight at low speed. The broth was centrifuged and the pellet (resin and cell mass) was extracted twice for $24 \mathrm{~h}$ with $\mathrm{Me}_{2} \mathrm{CO}\left(6 \mathrm{~L}\right.$ in total). Filtration of the extract and removal of the solvent under vacuum at $38^{\circ} \mathrm{C}$ afforded a solid residue, which was partitioned between EtOAc and $\mathrm{H}_{2} \mathrm{O}$. Evaporation of the solvent of the EtOAc soluble fraction in vacuo afforded a dark red oily residue $(533.9 \mathrm{mg})$ that was subjected to vacuum column chromatography on silica gel, using cyclohexane with increasing amounts of EtOAc, followed by EtOAc with increasing amounts of $\mathrm{MeOH}$ as the mobile phase, to yield 14 fractions (980A-980N). Fraction 980 (5\% MeOH in EtOAc, $26.8 \mathrm{mg}$ ) was purified by normal-phase HPLC, using cyclohexane/ $\mathrm{Me}_{2} \mathrm{CO}(50: 50)$ as eluent, to yield $4(11.2 \mathrm{mg})$ and 8 (3.3 mg). Fraction $980 \mathrm{~K}(10 \% \mathrm{MeOH}$ in EtOAc, $51.8 \mathrm{mg}$ ) was repeatedly purified by normal-phase HPLC, using cyclohexane/acetone (30:70 and 20:80) as eluent, and reversed-phase HPLC, using $\mathrm{MeCN} / \mathrm{H}_{2} \mathrm{O}(20: 80$ and 30:70) as eluent, to yield $\mathbf{3}$ (4.4 mg), $\mathbf{4}$ (3.2 mg), $\mathbf{5}$ (4.1 mg), 8 (6.9 mg), 9 (2.1 mg), $\mathbf{1 1}(6.3 \mathrm{mg}), \mathbf{1 2}(0.9 \mathrm{mg}), \mathbf{1 4}(4.3 \mathrm{mg}), \mathbf{1 5}$ (1.6 mg), 19 (2.8 mg), $20(0.3 \mathrm{mg}), 21$ (1.3 mg), 26 (2.9 mg), and a mixture (1:1) of 30, and 31 (0.4 mg). Fraction 980L ( $25 \% \mathrm{MeOH}$ in EtOAc, $88.3 \mathrm{mg}$ ) was further fractionated by vacuum column chromatography on silica gel C-18, using $\mathrm{H}_{2} \mathrm{O}$ with increasing amounts of $\mathrm{MeOH}$ as the mobile phase, to afford 3 fractions (980L1-980L3). Fractions 980L1 (20\% $\mathrm{MeOH}$ in $\mathrm{H}_{2} \mathrm{O}, 32.3 \mathrm{mg}$ ) and 980L2 (40\% to $60 \% \mathrm{MeOH}$ 
in $\mathrm{H}_{2} \mathrm{O}, 11.8 \mathrm{mg}$ ) were combined and purified by reversed-phase $\mathrm{HPLC}$, using $\mathrm{MeOH} / \mathrm{H}_{2} \mathrm{O}(30: 70)$ as eluent, and subsequently normal-phase HPLC, using cyclohexane/ $\mathrm{Me}_{2} \mathrm{CO}(20: 80)$ as eluent, to yield 12 (1.0 mg), 16 (0.9 mg), 20 (1.9 mg), 24 (0.8 mg), 25 (0.5 mg), and 29 (1.7 mg).

cis-Cyclo(Pro-3-chloro-Tyr) (15): white solid; $[\alpha]_{D}^{20}+69.0\left(c 0.021, \mathrm{CHCl}_{3}\right) ; \mathrm{UV}\left(\mathrm{CHCl}_{3}\right) \lambda_{\max }(\log$ ع) 240 (2.68), 280 (2.90) nm; IR (thin film) $v_{\max } 3231,2928,1651,1457,1295 \mathrm{~cm}^{-1}$; ${ }^{1} \mathrm{H}$ NMR data, see

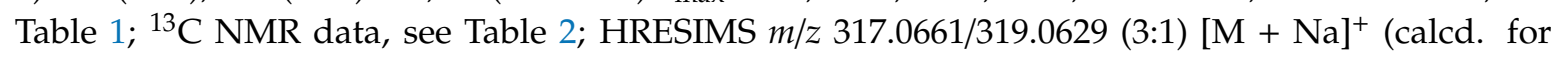
$\left.\mathrm{C}_{14} \mathrm{H}_{15} \mathrm{~N}_{2} \mathrm{O}_{3}{ }^{35} \mathrm{ClNa}, 317.0663, \mathrm{C}_{14} \mathrm{H}_{15} \mathrm{~N}_{2} \mathrm{O}_{3}{ }^{37} \mathrm{ClNa}, 319.0634\right)$.

trans-Cyclo(Pro-3-chloro-Tyr) (16): white solid; $[\alpha]_{D}^{20}+87.0\left(\right.$ ( $\left.0.023, \mathrm{CHCl}_{3}\right)$; $\mathrm{UV}\left(\mathrm{CHCl}_{3}\right) \lambda_{\max }$ (log $\varepsilon) 240$ (2.79), 280 (2.97) nm; IR (thin film) $v_{\max } 3235,2929,1650,1455,1293 \mathrm{~cm}^{-1}$; ${ }^{1} \mathrm{H}$ NMR data, see Table $1 ;{ }^{13} \mathrm{C}$ NMR data, see Table 2; HRESIMS m/z 317.0657/319.0627 (3:1) [M + Na] ${ }^{+}$(calcd. for $\mathrm{C}_{14} \mathrm{H}_{15} \mathrm{~N}_{2} \mathrm{O}_{3}{ }^{35} \mathrm{ClNa}$, 317.0663, $\mathrm{C}_{14} \mathrm{H}_{15} \mathrm{~N}_{2} \mathrm{O}_{3}{ }^{37} \mathrm{ClNa}$, 319.0634).

cis-Cyclo(3-chloro-Tyr-Ile) (31): white solid; ${ }^{1} \mathrm{H}$ NMR data, see Table $1 ;{ }^{13} \mathrm{C}$ NMR data, see Table 2; EIMS m/z 310/312 (3:1) [M] (calcd. for $\mathrm{C}_{15} \mathrm{H}_{19} \mathrm{~N}_{2} \mathrm{O}_{3} \mathrm{Cl}, 310 / 312$ ).

\section{Conclusions}

The chemical investigation of the organic extracts of the fermentation broths of five marine-derived strains isolated from sediments collected from the East Mediterranean Sea resulted in the isolation and structure elucidation of three new 2,5-DKPs, namely cis-cyclo(Pro-3-chloro-Tyr) (15), trans-cyclo(Pro-3-chloro-Tyr) (16), and cis-cyclo(3-chloro-Tyr-Ile) (31). It is not unusual for marine macro- and microorganisms to incorporate halogens, mainly chlorine and bromine atoms, in their secondary metabolism, in order to increase the bioactivity of the compounds they biosynthesize $[57,58]$. Indeed, the brominated analogues of $\mathbf{1 5}$ and $\mathbf{1 6}$ have already been isolated from the actinobacterium Nocardia ignorata [59]. Additionally, the relevant literature is supplemented with complete NMR assignments and revisions for 29 previously reported 2,5-DKPs.

Supplementary Materials: The following are available online at, Figures S1-S17: 1D and 2D NMR and MS spectra of compounds 15, 16 \& 31 .

Author Contributions: Conceptualization, V.R. and E.I.; methodology, M.H., E.K., P.G. and E.I.; investigation, M.H., E.K., P.G. and E.I.; resources, V.R. and E.I.; writing-Original draft preparation, M.H. and E.I.; writing-Review and editing, V.R. and E.I.; visualization, M.H. and E.I.; supervision, E.I.; funding acquisition, V.R. and E.I. All authors have read and agreed to the published version of the manuscript.

Funding: This work was partially supported by the project ARISTEIA-2587 "BIOMARACT", which was implemented under the "ARISTEIA" Action of the Operational Programme "EDUCATION AND LIFELONG LEARNING" and was co-funded by the European Social Fund (ESF) and National Resources.

Acknowledgments: M.H. gratefully acknowledges the Department of Scholarships and Awards of the National and Kapodistrian University of Athens for a PhD fellowship from Antonios Papadakis bequest. The authors thank A. Makris (Institute of Applied Biosciences/CERTH, Thessaloniki, Greece) for the identification of the bacterial strains.

Conflicts of Interest: The authors declare no conflict of interest. The funding sponsors had no role in the design of the study; in the collection, analyses, or interpretation of data; in the writing of the manuscript, and in the decision to publish the results.

\section{References}

1. Huang, R.; Zhou, X.; Xu, T.; Yang, X.; Liu, Y. Diketopiperazines from marine organisms. Chem. Biodivers. 2010, 7, 2809-2829. [CrossRef]

2. Huang, R.-M.; Yi, X.-X.; Zhou, Y.; Su, X.; Peng, Y.; Gao, C.-H. An update on 2,5-diketopiperazines from marine organisms. Mar. Drugs 2014, 12, 6213-6235. [CrossRef]

3. Prasad, C. Bioactive cyclic dipeptides. Peptides 1995, 16, 151-164. [CrossRef]

4. Borthwick, A.D. 2.5-Diketopiperazines: Synthesis, reactions, medicinal chemistry, and bioactive natural products. Chem. Rev. 2012, 112, 3641-3716. [CrossRef]

5. Ryan, L.A.M.; Dal Bello, F.; Arendt, E.K.; Koehler, P. Detection and quantitation of 2,5-diketopiperazines in wheat sourdough and bread. J. Agric. Food Chem. 2009, 57, 9563-9568. [CrossRef] [PubMed] 
6. Kumar, N.; Mohandas, C.; Nambisan, B.; Kumar, D.R.; Lankalapalli, R.S. Isolation of proline-based cyclic dipeptides from Bacillus sp. N strain associated with rhabitid entomopathogenic nematode and its antimicrobial properties. World J. Microbiol. Biotechnol. 2013, 29, 355-364. [CrossRef] [PubMed]

7. Furtado, N.A.J.C.; Pupo, M.T.; Carvalho, I.; Campo, V.L.; Duarte, M.C.T.; Bastos, J.K. Diketopiperazines produced by an Aspergillus fumigatus Brazilian strain. J. Braz. Chem. Soc. 2005, 16, 1448-1453. [CrossRef]

8. Mitova, M.; Tommonaro, G.; Hentschel, U.; Müller, W.E.G.; De Rosa, S. Exocellular cyclic dipeptides from a Ruegeria strain associated with cell cultures of Suberites domuncula. Mar. Biotechnol. 2004, 6, 95-103. [CrossRef] [PubMed]

9. Zheng, L.; Yan, X.; Chen, H.; Lin, W. Hymeniacidon perleve associated bioactive bacterium Pseudomonas sp. NJ6-3-1. Appl. Biochem. Microbiol. 2005, 41, 29-33. [CrossRef]

10. Lautru, S.; Gondry, M.; Genet, R.; Pernodet, J.-L. The albonoursin gene cluster of S. noursei: Biosynthesis of diketopiperazine metabolites independent of nonribosomal peptide synthetases. Chem. Biol. 2002, 9, 1355-1364. [CrossRef]

11. Sioud, S.; Karray-Rebai, I.; Aouissaoui, H.; Aigle, B.; Bejar, S.; Mellouli, L. Targeted gene disruption of the cyclo (L-Phe, L-Pro) biosynthetic pathway in Streptomyces sp. US24 strain. J. Biomed. Biotechnol. 2007, 2007, 91409. [CrossRef]

12. Schultz, A.W.; Oh, D.-C.; Carney, J.R.; Williamson, R.T.; Udwary, D.W.; Jensen, P.R.; Gould, S.J.; Fenical, W.; Moore, B.S. Biosynthesis and structures of cyclomarins and cyclomarazines, prenylated cyclic peptides of marine actinobacterial origin. J. Am. Chem. Soc. 2008, 130, 4507-4516. [CrossRef]

13. Martins, M.B.; Carvalho, I. Diketopiperazines: Biological activity and synthesis. Tetrahedron 2007, 63, 9923-9932. [CrossRef]

14. Cornacchia, C.; Cacciatore, I.; Baldassarre, L.; Mollica, A.; Feliciani, F.; Pinnen, F. 2,5-Diketopiperazines as neuroprotective agents. Mini Rev. Med. Chem. 2012, 12, 2-12. [CrossRef] [PubMed]

15. De Carvalho, M.P.; Abraham, W.-R. Antimicrobial and biofilm inhibiting diketopiperazines. Curr. Med. Chem. 2012, 19, 3564-3577. [CrossRef] [PubMed]

16. Wang, Y.; Wang, P.; Ma, H.; Zhu, W. Developments around the bioactive diketopiperazines: A patent review. Expert Opin. Ther. Patents 2013, 23, 1415-1433. [CrossRef] [PubMed]

17. Laville, R.; Nguyen, T.B.; Moriou, C.; Petek, S.; Debitus, C.; Al-Mourabit, A. Marine natural occurring 2,5-diketopiperazines: Isolation, synthesis and optical properties. Heterocycles 2015, 90, 1351-1366. [CrossRef]

18. Fischer, P.M. Diketopiperazines in peptide and combinatorial chemistry. J. Peptide Sci. 2003, 9, 9-35. [CrossRef]

19. Ressurreição, A.S.M.; Delatouche, R.; Gennari, C.; Piarulli, U. Bifunctional 2,5-diketopiperazines as rigid three-dimensional scaffolds in receptors and peptidomimetics. Eur. J. Org. Chem. 2011, 2, 217-228. [CrossRef]

20. Daugan, A.; Grondin, P.; Ruault, C.; Le Monnier de Gouville, A.C.; Coste, H.; Linget, J.M.; Kirilovsky, J.; Hyafil, F.; Labaudinière, R. The Discovery of Tadalafil: A novel and highly selective PDE5 inhibitor. 2: 2,3,6,7,12,12a-hexahydropyrazino $\left[1^{\prime}, 2^{\prime}: 1,6\right]$ pyrido[3,4-b]indole-1,4-dione analogues. J. Med. Chem. 2003, 46, 4533-4542. [CrossRef]

21. Liddle, J.; Allen, M.J.; Borthwick, A.D.; Brooks, D.P.; Davies, D.E.; Edwards, R.M.; Exall, A.M.; Hamlett, C.; Irving, W.R.; Mason, A.M.; et al. The discovery of GSK221149A: A potent and selective oxytocin antagonist. Bioorg. Med. Chem. Lett. 2008, 18, 90-94. [CrossRef] [PubMed]

22. Borthwick, A.D.; Liddle, J.; Davies, D.E.; Exall, A.M.; Hamlett, C.; Hickey, D.M.; Mason, A.M.; Smith, I.E.; Nerozzi, F.; Peace, S.; et al. Pyridyl-2,5-diketopiperazines as potent, selective, and orally bioavailable oxytocin antagonists: Synthesis, pharmacokinetics, and in vivo potency. J. Med. Chem. 2012, 26, 783-796. [CrossRef] [PubMed]

23. Crowley, S.; Mahony, J.; van Sinderen, D. Current perspectives on antifungal lactic acid bacteria as natural bio-preservatives. Trends Food Sci. Technol. 2013, 33, 93-109. [CrossRef]

24. Monbaliu, J.-C.M.; Hansen, F.K.; Beagle, L.K.; Panzner, M.J.; Steel, P.J.; Todadze, E.; Stevens, C.V.; Katritzky, A.R. A new benzotriazole-mediated stereoflexible gateway to hetero-2,5- diketopiperazines. Chem. Eur. J. 2012, 18, 2632-2638. [CrossRef] [PubMed]

25. Oleinikova, G.K.; Afiyatullov, S.S.; Mikhailov, V.V.; Shevchenko, L.S.; Menzorova, N.I.; Yurchenko, E.A. Diketopiperazines from marine isolate of actinobacterium Nocardiopsis umidischolae KMM 7036. Chem. Nat. Comp. 2015, 51, 192-193. [CrossRef] 
26. Huang, R.; Yan, T.; Peng, Y.; Zhou, X.; Yang, X.; Liu, Y. Diketopiperazines from the marine sponge Axinella sp. Chem. Nat. Comp. 2014, 50, 191-193. [CrossRef]

27. Chen, J.-H.; Lan, X.-P.; Liu, Y.; Jia, A.Q. The effects of diketopiperazines from Callyspongia sp. on release of cytokines and chemokines in cultured J774A.1 macrophages. Bioorg. Med. Chem. Lett. 2012, 22, 3177-3180. [CrossRef]

28. Takaya, Y.; Furukawa, T.; Miura, S.; Akutagawa, T.; Hotta, Y.; Ishikawa, N.; Niwa, M. Antioxidant constituents in distillation residue of Awamori spirits. J. Agric. Food Chem. 2007, 55, 75-79. [CrossRef]

29. Tezuka, Y.; Huang, Q.; Kikuchi, T.; Nishi, A.; Tubaki, K. Studies on the metabolites of mycoparasitic fungi. I. Metabolites of Cladobotryum varium. Chem. Pharm. Bull. 1994, 42, 2612-2617. [CrossRef]

30. Fdhila, F.; Vázquez, V.; Sánchez, J.L.; Riguera, R. DD-Diketopiperazines: Antibiotics active against Vibrio anguillarum isolated from marine bacteria associated with cultures of Pecten maximus. J. Nat. Prod. 2003, 66, 1299-1301. [CrossRef]

31. Adamczeski, M.; Reed, A.R.; Crews, P. New and known diketopiperazines from the Caribbean sponge Calyx cf. podatypa. J. Nat. Prod. 1995, 58, 201-208. [CrossRef]

32. Hellwig, V.; Dasenbrock, J.; Schumann, S.; Steglich, W.; Leonhardt, K.; Anke, T. New triquinane-type sesquiterpenoids from Macrocystidia cucumis (Basidiomycetes). Eur. J. Org. Chem. 1998, 1, 73-79. [CrossRef]

33. Hendea, D.; Laschat, S.; Baro, A.; Frey, W. Diastereoselective alkylation of a proline-derived bicyclic lactim ether. Helv. Chim. Acta 2006, 89, 1894-1909. [CrossRef]

34. Cronan, J.M., Jr.; Davidson, T.R.; Singleton, F.L.; Colwell, R.R.; Cardellina, J.H., II. Plant growth promoters isolated from a marine bacterium associated with Palythoa sp. Nat. Prod. Lett. 1998, 11, 271-278. [CrossRef]

35. Shigemori, H.; Tenma, M.; Shimazaki, K.; Kobayashi, J. Three new metabolites from the marine yeast Aureobasidium pullulans. J. Nat. Prod. 1998, 61, 696-698. [CrossRef]

36. Nalli, Y.; Gupta, S.; Khajuria, V.; Singh, V.P.; Sajgotra, M.; Ahmed, Z.; Thakur, N.L.; Ali, A. TNF- $\alpha$ and IL-6 inhibitory effects of cyclic dipeptides isolated from marine bacteria Streptomyces sp. Med. Chem. Res. 2017, 26, 93-100. [CrossRef]

37. He, R.; Wang, B.; Wakimoto, T.; Wang, M.; Zhu, L.; Abe, I. Cyclodipeptides from metagenomic library of a japanese marine sponge. J. Braz. Chem. Soc. 2013, 24, 1926-1932. [CrossRef]

38. Yang, X.-Q.; Yang, Y.-B.; Zhou, H.; He, G.-W.; Zhao, L.-X.; Xu, L.-H.; Ding, Z.-T. New megastigmane glycoside and alkaloids from Streptomyces sp. YIM 63342. Nat. Prod. Res. 2013, 27, 1191-1196. [CrossRef]

39. Sansinenea, E.; Salazar, F.; Jiménez, J.; Mendoza, A.; Ortiz, A. Diketopiperazines derivatives isolated from Bacillus thuringiensis and Bacillus endophyticus, establishment of their configuration by X-ray and their synthesis. Tetrahedron Lett. 2016, 57, 2604-2607. [CrossRef]

40. Wang, G.; Dai, S.; Chen, M.; Wu, H.; Xie, L.; Luo, X.; Li, X. Two diketopiperazine cyclo(Pro-Phe) isomers from marine bacteria Bacillus subtilis sp. 13-2. Chem. Nat. Comp. 2010, 46, 583-585. [CrossRef]

41. Adamczeski, M.; Quinoa, E.; Crews, P. Novel sponge-derived amino acids. 5. Structures, stereochemistry, and synthesis of several new heterocycles. J. Am. Chem. Soc. 1989, 111, 647-654. [CrossRef]

42. Kumar, S.N.; Nambisan, B.; Mohandas, C. Purification and identification of two antifungal cyclic dipeptides from Bacillus cereus subsp. thuringiensis associated with a rhabditid entomopathogenic nematode especially against Fusarium oxysporum. J. Enzyme Inhib. Med. Chem. 2014, 29, 190-197. [CrossRef] [PubMed]

43. Bobylev, M.M.; Bobyleva, L.I.; Strobel, G.A. Synthesis and bioactivity of analogs of maculosin, a host-specific phytotoxin produced by Alternaria alternata on spotted knapweed (Centaurea maculosa). J. Agric. Food Chem. 1996, 44, 3960-3964. [CrossRef]

44. Caballero, E.; Avendaño, C.; Menéndez, J.C. Brief total synthesis of the cell cycle inhibitor tryprostatin B and related preparation of its alanine analogue. J. Org. Chem. 2003, 68, 6944-6951. [CrossRef] [PubMed]

45. Grant, G.D.; Hunt, A.L.; Milne, P.J.; Roos, H.M.; Joubert, J.A. The structure and conformation of the tryptophanyl diketopiperazines cyclo(Trp-Trp) $\mathrm{C}_{2} \mathrm{H}_{6} \mathrm{SO}$ and cyclo(Trp-Pro). J. Chem. Crystallogr. 1999, 29, 435-447. [CrossRef]

46. Wei, J.; Zhang, X.-Y.; Deng, S.; Cao, L.; Xue, Q.-H.; Gao, J.-M. $\alpha$-Glucosidase inhibitors and phytotoxins from Streptomyces xanthophaeus. Nat. Prod. Res. 2017, 31, 2062-2066. [CrossRef]

47. Beagle, L.K.; Hansen, F.K.; Monbaliu, J.-C.M.; DesRosiers, M.P.; Phillips, A.M.; Stevens, C.V.; Katritzky, A.R. Efficient synthesis of 2,5-diketopiperazines by Staudinger-mediated cyclization. Synlett 2012, 23, 2337-2340. [CrossRef] 
48. Bérubé, C.; Barbeau, X.; Cardinal, S.; Boudreault, P.-L.; Bouchard, C.; Decley, N.; Lagüe, P.; Voyer, N. Interfacial supramolecular biomimetic epoxidation catalysed by cyclic dipeptides. Supramolecular Chem. 2017, 29, 330-349. [CrossRef]

49. Stark, T.; Hofmann, T. Structures, sensory activity, and dose/response functions of 2,5-diketopiperazines in roasted cocoa nibs (Theobroma cacao). J. Agric. Food Chem. 2005, 53, 7222-7231. [CrossRef]

50. Hawas, U.W.; Al-Farawati, R. Chemical constituents and antiviral activity from marine endophytic fungi from Red Sea alga Padina pavonica. J. Chem. Soc. Pak. 2017, 39, 478-483.

51. Gnanaprakasam, B.; Balaraman, E.; Ben-David, Y.; Milstein, D. Synthesis of peptides and pyrazines from $\beta$-amino alcohols through extrusion of $\mathrm{H}_{2}$ catalyzed by ruthenium pincer complexes: Ligand-controlled selectivity. Angew. Chem. Int. Ed. 2011, 50, 12240-12244. [CrossRef] [PubMed]

52. Nonappa; Ahonen, K.; Lahtinen, M.; Kolehmainen, E. Cyclic dipeptides: Catalyst/promoter free rapid and environmentally benign cyclization of free amino acids. Green Chem. 2011, 13, 1203-1209. [CrossRef]

53. Liu, X.; Li, H.; Zhou, F.; Wang, R. Secondary metabolites of Fusarium sp., an endophytic fungus in Astragalus membranaceus. Chem. Nat. Comp. 2015, 51, 1199-1201. [CrossRef]

54. Tullberg, M.; Grøtli, M.; Luthman, K. Efficient synthesis of 2,5-diketopiperazines using microwave assisted heating. Tetrahedron 2006, 62, 7484-7491. [CrossRef]

55. Guo, C.-J.; Yeh, H.-H.; Chiang, Y.-M.; Sanchez, J.F.; Chang, S.-L.; Bruno, K.S.; Wang, C.C.C. Biosynthetic pathway for the epipolythiodioxopiperazine acetylaranotin in Aspergillus terreus revealed by genome-based deletion analysis. J. Am. Chem. Soc. 2013, 135, 7205-7213. [CrossRef] [PubMed]

56. Bugni, T.S.; Woolery, M.; Kauffman, C.A.; Jensen, P.R.; Fenical, W. Bohemamines from a marine-derived Streptomyces sp. J. Nat. Prod. 2006, 69, 1626-1628. [CrossRef]

57. Cabrita, M.T.; Vale, C.; Rauter, A.P. Halogenated compounds from marine algae. Mar. Drugs 2010, 8, 2301-2317. [CrossRef]

58. Newmann, C.S.; Fujimori, D.G.; Walsh, C.T. Halogenation in natural product biosynthesis. Chem. Biol. 2008, 15, 99-109. [CrossRef]

59. Noel, A.; Ferron, S.; Rouaud, I.; Gouault, N.; Hurvois, J.P.; Tomasi, S. Isolation and structure identification of novel brominated diketopiperazines from Nocardia ignorata-A lichen-associated actinobacterium. Molecules 2017, 22, 371. [CrossRef]

Sample Availability: Samples of compounds 3, 4, 8, and 11 are available from the authors.

(C) 2020 by the authors. Licensee MDPI, Basel, Switzerland. This article is an open access article distributed under the terms and conditions of the Creative Commons Attribution (CC BY) license (http://creativecommons.org/licenses/by/4.0/). 